\title{
On the chemical bonding effects in the Raman response: Benzenethiol adsorbed on silver clusters
}

\author{
Semion K. Saikin,, , 2, , Roberto Olivares-Amaya, ${ }^{1}$ Dmitrij Rappoport,${ }^{1}$ Michael Stopa,${ }^{3}$ and Alán Aspuru-Guzik ${ }^{1}$, \\ ${ }^{1}$ Department of Chemistry and Chemical Biology, \\ Harvard University, Cambridge, MA 02138, USA. \\ ${ }^{2}$ Department of Physics, Kazan State University, Kazan 420008, Russian Federation. \\ ${ }^{3}$ Center for Nanoscale Systems, Harvard University, Cambridge, MA 02138, USA.
}

\begin{abstract}
We study the effects of chemical bonding on Raman scattering from benzenethiol chemisorbed on silver clusters using time-dependent density functional theory (TDDFT). Raman scattering cross sections are computed using a formalism that employs analytical derivatives of frequency-dependent electronic polarizabilities, which treats both off-resonant and resonant enhancement within the same scheme. In the off-resonant regime, Raman scattering into molecular vibrational modes is enhanced by one order of magnitude and shows pronounced dependence on the orientation and the local symmetry of the molecule. Additional strong enhancement of the order of $10^{2}$ arises from resonant transitions to mixed metal-molecular electronic states. The Raman enhancement is analyzed using Raman excitation profiles (REPs) for the range of excitation energies $1.6-3.0 \mathrm{eV}$, in which isolated benzenethiol does not have electronic transitions. The computed vibrational frequency shifts and relative Raman scattering cross sections of the metal-molecular complexes are in good agreement with experimental data on surface enhanced Raman scattering (SERS) for benzenethiol adsorbed on silver surfaces. Characterization and understanding of these effects, associated with chemical enhancement mechanism, may be used to improve the detection sensitivity in molecular Raman scattering.
\end{abstract}

\section{INTRODUCTION}

Raman scattering from molecules in proximity to a rough noble-metal surface or near a metal nanoparticle is strongly enhanced due to the interaction with surface plasmon modes and to the formation of metal-molecular complexes $\frac{1,2}{=3}$ This phenomenon, which allows for the measurement of Raman spectra of extremely low concentrations of molecules ${ }^{3}$ with a single-molecule detection as its ultimate limit,,$\underline{4,5}$ is very attractive for sensor applications. In particular, it could be utilized for detection and identification of hazardous materials $\stackrel{6.7}{\underline{7}}$ or for probing of biological structures, $\stackrel{8}{=}$ for which Raman fingerprints provide unique information about molecular composition.

Recent achievements in the design of nanostructured materials demonstrate substantial progress toward resolving the long-standing problem of low reproducibility of SERS substrates. Arrays of nanoantennas fabricated with electron beam lithography ${ }^{9}$ or nanoimprinting ${ }^{10}$ utilize extended control of optically excited surface plasmons to tune the plasmon resonance frequency and to focus the near field in particular areas. Lithographically engineered 11,12 or laserengineered ${ }^{13}$ structures allow the observation of a spatially homogeneous enhancement of the Raman signal by 7 orders of magnitude $\underline{\underline{14}}$ when an excitation laser frequency far below intramolecular resonances is employed. However, there remains a number of open questions which are related to the formation of hot spots and to the homogeneity of the Raman response throughout a sample. The enormous Raman cross section reported for fluorescent dyes in hot spots $\stackrel{4}{*}$ has a substantial contribution from an intramolecular resonant excitation $\stackrel{15}{=}$ On the other hand, many important analytes do not have electronic excitations in the available range of laser frequencies. For these systems, a relevant question is whether modification of the local environment of the molecule can be used to boost the limit of Raman detection sensitivity.

The importance of the so-called chemical enhancement1,16,17 has been debated since the early years after the discovery of SERS. The contributions of the electromagnetic coupling and the chemical binding are not clearly separable in the experiments, $\stackrel{17}{=}$ because the first process is essential for SERS detection. This adds to ambiguity in the interpretation of SERS experiments. Moreover, the electronic coupling effects are sensitive to the local environment of adsorbed molecules, which makes a systematic analysis of chemical effects more difficult. General theories of chemical enhancement $\frac{18,19,20}{1}$ provide an intuitive picture of the mechanism, but rely on phenomenological parameters. In this context, first-principles modeling 21 is a useful tool that complements experimental studies and provides additional information about microscopic properties of a metal surface/adsorbed molecule interface.

Complete modeling of a molecule chemisorbed on a rough metal surface requires multi-scale simulations, in which the electronic structure of a molecule and its local environment are treated by quantum chemical methods while a larger-scale environment is accounted for by a mean-field approximation. However, to understand the chemical bonding effects in SERS, it is enough to simulate only the local environment of a molecule. This is consistent with the "adatom model" $\frac{1}{,}$ which assumes that the atomic-scale roughness features determine the hot spots on a metal 
surface. Obviously, such an approach does not account for the electromagnetic enhancement due to the excitation of surface plasmons in the metal. An interference between the chemical and the electromagnetic effects is ignored as well. To get the total enhancement factor one has to use a conventional phenomenological relation 16 which assumes that both effects enter in multiplicative fashion. In most previous theoretical studies of SERS, only a few metal atoms were used to model the molecule/surface interaction. For instance, in Ref ${ }^{22}$ the authors considered a complex with a single $\mathrm{Ag}$ atom to mimic a chemisorption of phthalimide on a silver surface and obtained a reasonable agreement with experiments. Recently, Schatz and co-workers reported a resonance Raman response calculation procedure using phenomenological lifetime parameters for electronic polarizability derivatives $\stackrel{23}{2}$ This procedure has been applied to study SERS of pyridine adsorbed on silver clusters up to a few tens of atoms $24,25,26$ The authors identified three different mechanisms contributing to SERS: change in static polarizability of the molecule upon adsorption, resonant enhancement due to charge-transfer transitions, and electromagnetic enhancement due to coupling with a strong excitation in a metal cluster, and discussed their role in SERS. In Ref $\underline{26}$ some examples of different molecules and pyridine with substituents have been considered. However, no systematic studies of other molecular structures have been done yet. Given the differences in the chemical bonding of pyridine and thiols to metal surfaces, it is important to know how general these findings are and whether they can be applied to other types of metal-molecular coupling or to other molecules.

In this paper, we address effects related to chemical bonding on Raman scattering from benzenethiol adsorbed on silver clusters $\mathrm{Ag}_{n}, n=6-11$, which is one of the most commonly used analytes in SERS experiments. We link the enhancement of Raman response to the modification of the molecular electronic structure due to adsorption. Excitation energies and transition moments of the metal-molecular complexes are substantially different from those of bare metal clusters and of isolated benzenethiol. For off-resonant excitations, Raman response is enhanced by one order of magnitude. To understand the importance of the cluster geometry, we modeled a pool of 7 different metalmolecular complexes. We identify the effects that contribute to the off-resonant Raman enhancement, such as the molecular orientational effect, the effect of the local symmetry of the adsorbate, and the effect of the proximity of the vibrational mode to a binding site. Stochastic modulation of these effects by thermal motion is related to "blinking" events observed in recent SERS experiments on 4-aminobenzenethiol, 27,28 We compare the computed vibrational frequency shifts and relative Raman scattering cross sections of the the metal-molecular complexes to experimental SERS data for benzenethiol adsorbed on silver surfaces $\frac{1,2,3,32}{2}$

Our theoretical approach to compute Raman scattering cross section is based on analytical derivatives of frequencydependent polarizabilities $\stackrel{33}{3}$ The frequency dependence of polarizability derivatives includes resonance enhancement effects in an approximate fashion, which allows us to describe both off-resonance and resonance enhancement effects on an equal footing and to study resonance excitation profiles of Raman scattering cross sections. However, this approach does not take into account the finite lifetime of the excited states. As a result, the Raman scattering cross sections computed within our approach diverge in the strictly resonant case.

We demonstrate that formation of mixed metal-molecular electronic states results in a resonance structure in the Raman excitation profiles (REPs) for molecular vibrations within the excitation range $1.6-3.0 \mathrm{eV}$, which is far below the purely intramolecular transitions. Our lower-bound estimates of the Raman signal enhancement due to chemical bonding is of the order of $10^{2}-10^{3}$ in the absence of intramolecular resonances. The chemical bonding effect thus provides additional flexibility in controlling the enhancement of Raman scattering from chemisorbed species.

The paper is organized as follows: in Sec. I we describe the details of our computational procedure. In Sec. IIA IIID the computed results are presented and different mechanisms contributing to the Raman enhancement are discussed. In particular, we show that the orientation of the benzene ring has a substantial effect on the Raman scattering cross section. We also identify metal-molecular states responsible for the resonant enhancement of the Raman response of the computed complexes. In Sec. IIIE the computed Raman spectra are compared to available experimental data. The conclusions are formulated in Sec. IV.

\section{COMPUTATIONAL DETAILS}

Density functional calculations were performed using the quantum chemistry package Turbomole, version $5.10 . \underline{34}$ Triple- $\zeta$ valence-polarization basis sets (def2-TZVP 35 ) were used for the main group elements while for silver atoms we employed split-valence basis sets with polarization (def2-SV $(\mathrm{P}) \stackrel{36}{36}$ ) and effective core potentials (ECP) comprising the 28 core electrons and accounting for scalar relativistic effects $\frac{37}{2}$ Preliminary calculations showed that expanding the molecular basis set up to quadruple- $\zeta$ quality ${ }^{35}$ does not significantly alter the results.

Our choice of the computed exchange-correlation functional was guided by the balance between the accuracy of the computed Raman scattering cross sections and an accurate description of electronic and geometric parameters of $\mathrm{Ag}_{n}$ clusters. We chose the hybrid functional of Perdew, Burke, and Ernzerhof (PBE0) ${ }^{38}$ which provides good accuracy for frequency-dependent polarizabilities and Raman scattering cross sections 39.40 While many computational studies of 
metal clusters have been traditionally performed with gradient-corrected exchange-correlation functionals, $\underset{41,42}{,}$ hybrid functionals were found to yield good structural parameters and band gaps in extended systems $\underline{\underline{43}}$

The charge-transfer error of approximate exchange-correlation functionals is a significant challenge in TDDFT calculations, although several recent works have proposed approaches to address this problem. $\underline{44,45,46,47}$ The chargetransfer error results in an overestimation of electronic polarizabilities and an underestimation of electronic excitation energies, however these effects are ameliorated by inclusion of a fraction of non-local Hartree-Fock exchange in hybrid

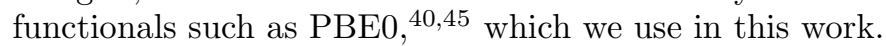

Ground state structure optimizations of silver clusters $\mathrm{Ag}_{n}$ with $n=6-11$ were performed using the PBE0 functional. Force-constant calculations were used to confirm that the optimized structures correspond to local minima of the

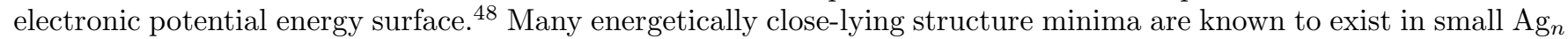
clusters $1,49,50$. We concentrated on structures suitable to represent atomic-scale roughness features, especially those with pyramidal or bipyramidal shape. For instance, for the $\mathrm{Ag}_{6}$ cluster the pyramidal $C_{5 v}$ isomer, which might be considered as a more realistic model for atomic-scale roughness, rather than the lowest-energy planar structure of $D_{3 h}$ symmetry 11,49 was used. For each optimized cluster structure, the 200 lowest electronic excitations were computed using TDDFT in the frequency-based linear response regime $51,52,53$ The obtained line spectra were broadened using an empirical Gaussian broadening parameter of $0.05 \mathrm{eV}$.

Oxidative attachment of the benzenethiol molecule ${ }^{54,55}$ was modeled by placing the benzenethiol radical (PhS) at different atomic binding sites and fully reoptimizing the structures of the $\mathrm{PhS}-\mathrm{Ag}_{n}$ complexes. Raman spectra of benzenethiol and $\mathrm{PhS}-\mathrm{Ag}_{n}$ complexes were obtained from analytical derivatives of frequency-dependent polarizabilities ${ }^{33}$ This approach is based on the polarizability Lagrangian and allows for efficient computation of Raman spectra of medium-sized and large molecules. Raman spectra of benzenethiol and $\mathrm{PhS}-\mathrm{Ag}_{n}$ complexes were computed for a low-energy excitation of $0.62 \mathrm{eV}(2000 \mathrm{~nm})$ to investigate the off-resonance Raman scattering enhancement. Raman excitation profiles of benzenethiol and $\mathrm{PhS}-\mathrm{Ag}_{n}$ were computed for the range of 1.6-3.0 eV for the four strongest vibrational modes of the benzenethiolate group. No scaling of vibrational frequencies was applied. The Raman spectra were simulated by Lorentzian broadening of the line spectra using an empirical linewidth of $5 \mathrm{~cm}^{-1}$. A scattering angle of 90 degrees and perpendicular polarization of both incident and scattered radiation was assumed unless specified otherwise.

\section{RESULTS AND DISCUSSION}

\section{A. Silver Clusters and Metal-Molecular Complexes}

The computed structures of the clusters $\mathrm{Ag}_{n}, n=6-11$, are in agreement with results of previous works. $\stackrel{41}{=}$ The clusters with an even number of atoms $n$ were found to be closed-shell singlets while the odd-numbered clusters are spin doublets. The relative energies of the structures are dependent on the particular choice of the exchangecorrelation functional. Among the simulated structures, several metal clusters were selected based on their similarity in geometry. In particular, the geometries derived from the bipyramidal structure of $\mathrm{Ag}_{7}$ were chosen.

The benzenethiol molecule binds to the Ag metal surface via the thiolate bond. To construct the metal-molecular complexes the central atom of the bipyramid has been chosen as a binding site. The final optimized geometries of $\mathrm{PhS}-\mathrm{Ag}_{n}, n=6-11$, are shown in Fig. [1. In most configurations the sulfur atom migrates to the middle of an $\mathrm{Ag}-\mathrm{Ag}$ bond forming a bridging motif. This is consistent with previous theoretical studies of benzenethiol chemisorbed on Au surfaces ${ }^{56}$ For a better understanding of properties of the $\mathrm{PhS}-\mathrm{Ag}_{n}$ complexes the simplest structure - benzenethiol bound to a single $\mathrm{Ag}$ atom - has been simulated. Addition of benzenethiol to the $C_{5 v}$-symmetric $\mathrm{Ag}_{6}$ cluster leads to a rearrangement of the metal atoms to form a $C_{2 v}$-symmetric cluster structure, see Fig. 1 . However, we find that the $C_{2 v}$ structure of $\mathrm{Ag}_{6}$ does not correspond to a local minimum for the PBE0 functional. Starting with approximately similar initial conditions, two stable isomers of the $\mathrm{PhS}-\mathrm{Ag}_{7}$ complex with an on-top and a bridging binding motif have been obtained, respectively. The energy difference between these two structures is approximately $3 \mathrm{kcal} / \mathrm{mol}$, with the lower configuration corresponding to the complex with the bridging motif.

The structural characteristics of the $\mathrm{PhS}-\mathrm{Ag}_{n}, n=1,6-11$, complexes are given in Tab. [ They include the lengths of the $\mathrm{Ag}-\mathrm{S}$ and the $\mathrm{S}-\mathrm{C}$ bonds, the angle $\mathrm{C}-\mathrm{S}-\mathrm{Ag}$ (for the bridging motif the calculated angle is between the $\mathrm{S}-\mathrm{C}$ bond and a shortest line connecting the sulfur atom with the nearest $\mathrm{Ag}-\mathrm{Ag}$ bond), and the distance between the carbon atom adjacent to the $\mathrm{S}-\mathrm{C}$ bond and the closest silver atom. The latter parameter characterizes the shortest non-bonding distance between the benzene ring and the $\mathrm{Ag}_{n}$ cluster. The binding energies between benzenethiol and silver clusters were estimated as

$$
E_{b}\left(\mathrm{PhS}-\mathrm{Ag}_{n}\right)=E\left(\mathrm{Ag}_{n}\right)+E(\mathrm{PhSH})-E\left(\mathrm{PhS}-\mathrm{Ag}_{n}\right)-\frac{1}{2} E\left(\mathrm{H}_{2}\right),
$$


FIG. 1: Optimized geometries of $\mathrm{PhS}-\mathrm{Ag}_{n}, n=6-11$ complexes that were utilized in the study. For $n=7$ two isomers with different types of binding for the molecule were considered.

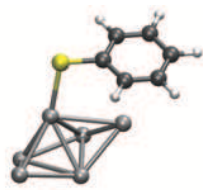

$\mathrm{PhS}-\mathrm{Ag}_{6}$

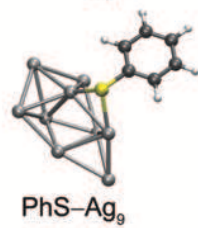

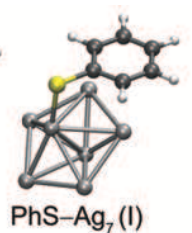

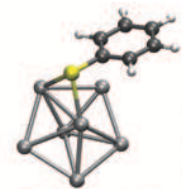

$\mathrm{PhS}-\mathrm{Ag}_{7}$ (II)

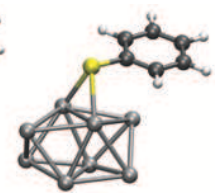

$\mathrm{PhS}-\mathrm{Ag}_{8}$

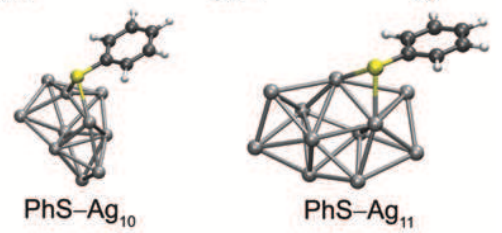

TABLE I: The computed structural properties of $\mathrm{PhS}-\mathrm{Ag}_{n}, n=1,6-11$, complexes. The lengths of the Ag-S and the $\mathrm{C}-\mathrm{S}$ bonds, and the shortest distance between the aromatic ring and the cluster, $\mathrm{C}_{2}-\mathrm{Ag}$, are given in å. The $\mathrm{C}_{2}$ denotes a carbon atom adjacent to the $\mathrm{C}-\mathrm{S}$ bond. The angle $\mathrm{C}-\mathrm{S}-\mathrm{Ag}$ is given in degrees and the binding energy of a molecule and a cluster is calculated according to Eq. 1 in $\mathrm{kcal} / \mathrm{mol}$.

\begin{tabular}{|l|c|c|c|c|c|c|}
\hline Complex & Binding & $\mathrm{Ag}-\mathrm{S}$ & $\mathrm{C}-\mathrm{S}$ & $\angle \mathrm{C}-\mathrm{S}-\mathrm{Ag}$ & $\mathrm{C}_{2}-\mathrm{Ag}$ & $E_{b}$ \\
\hline $\mathrm{PhS}-\mathrm{Ag}_{1}$ & on-top & 2.339 & 1.769 & 102.830 & 3.975 & 12.34 \\
$\mathrm{PhS}-\mathrm{Ag}_{6}$ & on-top & 2.389 & 1.756 & 101.470 & 2.454 & 7.56 \\
$\mathrm{PhS}-\mathrm{Ag}_{7}(\mathrm{I})$ & on-top & 2.421 & 1.757 & 96.606 & 2.669 & 17.71 \\
$\mathrm{PhS}-\mathrm{Ag}_{7}(\mathrm{II})$ & bridge & $2.521 / 2.589$ & 1.768 & 103.673 & 2.629 & 20.67 \\
$\mathrm{PhS}-\mathrm{Ag}_{8}$ & bridge & $2.573 / 2.587$ & 1.767 & 109.449 & 2.600 & 3.31 \\
$\mathrm{PhS}-\mathrm{Ag}_{9}$ & bridge & $2.429 / 2.458$ & 1.774 & 109.682 & 3.646 & 25.06 \\
$\mathrm{PhS}-\mathrm{Ag}_{10}$ & bridge & $2.480 / 2.495$ & 1.769 & 108.946 & 3.684 & 15.37 \\
$\mathrm{PhS}-\mathrm{Ag}_{11}$ & bridge & $2.544 / 2.546$ & 1.768 & 105.044 & 2.523 & 23.32 \\
\hline
\end{tabular}

neglecting the basis set superposition errors $\frac{57}{5}$ The variation of the $\mathrm{Ag}-\mathrm{S}$ and $\mathrm{C}-\mathrm{S}$ bond lengths for the complexes with the same type of binding is less than $4 \%$. The angle between the $\mathrm{C}-\mathrm{S}$ and $\mathrm{Ag}-\mathrm{S}$ bonds is consistent with the experimental data obtained for benzenethiol adsorbed on $\mathrm{Au}$ (111) $\stackrel{58}{\underline{6}}$ There are no obvious correlations of the structure parameters with the size of the $\mathrm{Ag}_{n}$ clusters. The binding energies vary substantially for the complexes. $\mathrm{PhS}-\mathrm{Ag}_{n}$ complexes with odd $n$ form closed-shell electronic configurations and have larger binding energies.

Two types of benzene ring orientation are distinguishable. In the complexes $\mathrm{PhS}-\mathrm{Ag}_{n}, n=6,7,8,11$ the benzene ring oriented towards the metal cluster, allowing several non-bonding $\mathrm{C}-\mathrm{Ag}$ interactions. In the complexes $\mathrm{PhS}-\mathrm{Ag}_{n}$, $n=9,10$ the benzene ring is directed outward and the distance between the ring and the $\mathrm{Ag}_{n}$ cluster is about $40 \%$ longer than in the previous type.

In the following sections, we provide a detailed analysis of the computed optical and Raman spectra of $\mathrm{PhS}-\mathrm{Ag}_{n}$ complexes using representative examples of the aforementioned binding structures and molecule orientations. The spectra of the other complexes are provided in the Supplementary Information.

\section{B. Electronic Excitation Spectra.}

The electronic excitations of neat benzenethiol are in the ultraviolet spectral range. The computed energies of the two lowest $a^{\prime}$ transitions, $4.87 \mathrm{eV}$ and $5.37 \mathrm{eV}$, are in good agreement with the measured values of $4.42 \mathrm{eV}$ and $5.25 \mathrm{eV}$ for benzenethiol in a solution, respectively $\underline{\underline{59}}$ The simulated absorption spectra of bare silver clusters are consistent with the experimental data from Ref. $\underline{41}$. In the energy range of 3-5 eV, the clusters of higher symmetry, such as $\operatorname{Ag}_{7}\left(D_{5 h}\right)$ and $\operatorname{Ag}_{10}\left(D_{2 d}\right)$, have few strong transitions with oscillator strengths higher than 1 . The low-frequency parts of the absorption spectra overlap with the visible range and some extend down to $0.5 \mathrm{eV}$. They consist of weak 

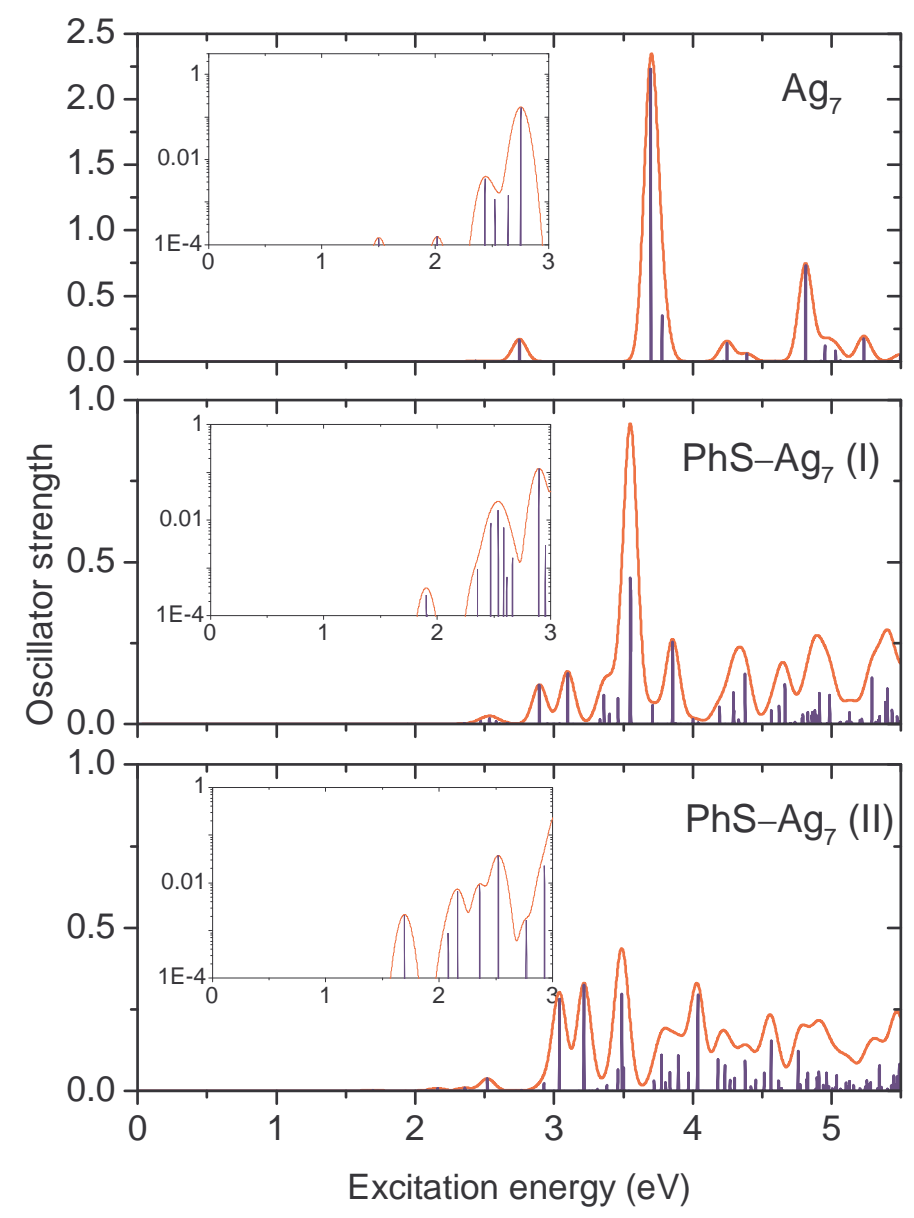

FIG. 2: Electronic excitation spectra of $\mathrm{Ag}_{7}$ cluster and two isomers of the $\mathrm{PhS}-\mathrm{Ag}_{7}$ complex with different types of binding on-top and bridge. The insets show the low-frequency parts of the spectra in logarithmic scale for the range $1.0-3.0 \mathrm{eV}$.

transitions with oscillator strengths in the range $10^{-1}-10^{-4}$. As an example, the electronic excitation spectra of the $\mathrm{Ag}_{7}$ cluster and two isomeric complexes $\mathrm{PhS}-\mathrm{Ag}_{7}$ (I) and (II) are shown in Fig. 2 The spectra of the complexes differ substantially from the spectra of the corresponding silver clusters. In contrast to silver-pyridine complexes $\stackrel{25}{,}$ the strong electronic transitions are quenched in most of the studied $\mathrm{PhS}-\mathrm{Ag}_{n}$ structures. In the cases where these excitations are still identifiable, we observe a red-shift of the order of $0.1-0.2 \mathrm{eV}$, see Fig. 2] except for the $\mathrm{PhS}-\mathrm{Ag}_{10}$ complex where the transition is blue-shifted by about $0.1 \mathrm{eV}$.

\section{Off-Resonance Raman Spectra}

Off-resonance Raman spectra of benzenethiol and of $\mathrm{PhS}-\mathrm{Ag}_{n}, n=6-11$, complexes were simulated using an excitation energy of $0.62 \mathrm{eV}(2000 \mathrm{~nm})$, which is below the lowest electronic transition in these systems. Three different quantities have been computed: Raman cross sections for characteristic molecular vibrational modes; the total scattering cross section of the complex, and the integrated cross section with a low-frequency cutoff at $200 \mathrm{~cm}^{-1}$. The latter quantity excludes almost all vibrational modes of the metal cluster. Most important for SERS applications are molecular vibrational modes about $1000 \mathrm{~cm}^{-1}$. Enhancement of the scattering cross sections of these modes is used to characterize the surface enhancement. However, the integrated cross sections are introduced to analyze the modulations of the Raman response rather than for estimation of the enhancement factor. The computed Raman spectra are given in Fig. 3 .

The computed Raman spectrum of isolated benzenethiol is in reasonable agreement with the experimental offresonant spectrum of neat benzenethiol recorded for a $785 \mathrm{~nm}$ excitation $\stackrel{1}{*}$ The dominant vibrational modes in the Raman spectrum of benzenethiol are totally symmetric and belong to the $a^{\prime}$ irreducible representation of the $C_{s}$ 


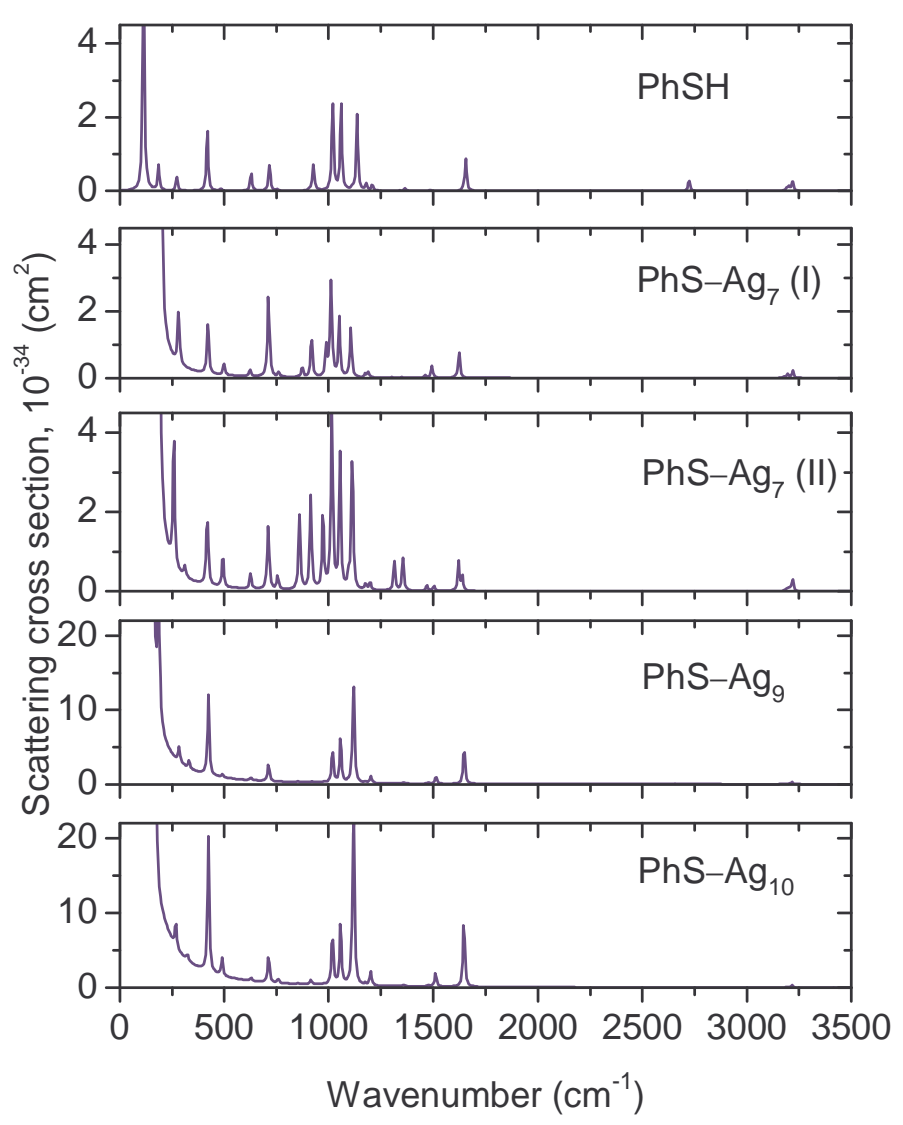

FIG. 3: The computed Raman spectra of isolated benzenethiol ( $\mathrm{PhSH}$ ) and four different complexes $\mathrm{PhS}-\mathrm{Ag}_{7}$ (I) and (II), $\mathrm{PhS}-\mathrm{Ag}_{9}$, and $\mathrm{PhS}-\mathrm{Ag}_{10}$ for the excitation energy $0.62 \mathrm{eV}(2000 \mathrm{~nm})$, which is below all electronic transitions in the complexes.

point group. The computed vibrational band at $\omega_{1}=1019 \mathrm{~cm}^{-1}$ is assigned to the ring breathing mode, and the band at $\omega_{2}=1059 \mathrm{~cm}^{-1}$ corresponds to a ring deformation mode. The $\mathrm{C}-\mathrm{S}$ stretching mode is computed at $\omega_{3}=1136 \mathrm{~cm}^{-1}$ while the computed Raman band at $\omega_{4}=1656 \mathrm{~cm}^{-1}$ is associated with a totally symmetric ring stretching mode. Our results are consistent with previous assignments $\underline{\underline{60}}$ The computed vibrational frequencies of benzenethiol are blue-shifted by $10-50 \mathrm{~cm}^{-1}$ with respect to experimental data due to incomplete basis sets and neglect of anharmonicity. The totally symmetric modes assigned above correspond to the experimentally measured vibrational frequencies $\omega_{1}^{\exp }=1004 \mathrm{~cm}^{-1}, \omega_{2}^{\exp }=1027 \mathrm{~cm}^{-1}, \omega_{3}^{\exp }=1094 \mathrm{~cm}^{-1}$, and $\omega_{4}^{\exp }=1583 \mathrm{~cm}^{-1}$, respectively, for neat benzenethiol. $\frac{1}{}$ Comparison of computed Raman intensities of isolated benzenethiol to experimental data is provided in the Supplementary Information.

Binding of benzenethiol to $\mathrm{Ag}_{n}$ clusters leads to an overall increase of off-resonant Raman scattering cross sections and to a significant redistribution of band intensities in the Raman spectrum. This effect is known as the static enhancement mechanism of SERS 1 This effect has been attributed to the decrease of the energy gap between the highest occupied molecular orbital (HOMO) and the lowest unoccupied molecular orbital (LUMO) and the ensuing enhancement of the electronic polarizability and its derivatives $\stackrel{26}{2}$ The Raman cross section of the molecular vibrational modes $\omega_{1-4}$ in the computed metal-molecular complexes can be up to 10 times larger than that in isolated benzenethiol. This value is comparable to the results of Ref $\underline{24}$ for pyridine. However, we observe a strong dependence of the enhancement factor on the geometry of a metal cluster and the orientation of the molecule. For example, the Raman signal from the modes $\omega_{1-4}$ in $\mathrm{PhS}-\mathrm{Ag}_{7}$ (I and II) complexes is almost unenhanced compared to PhSH, see Fig. 3 . Also, Raman signals from different molecular modes have different enhancement factors. To characterize the offresonant enhancement of Raman scattering, the cross sections of the $\omega_{4}$ vibrational mode have been used. Tab. III shows the computed off-resonant electronic polarizabilities, HOMO-LUMO gaps, Raman cross sections corresponding to the $\omega_{4}$ vibrational mode, and integrated Raman scattering cross sections of benzenethiol and $\mathrm{PhS}-\mathrm{Ag}_{n}$ complexes for the excitation energy of $0.62 \mathrm{eV}(2000 \mathrm{~nm})$. The integrated cross sections are computed by summation of Raman scattering cross sections over all vibrational modes of the complex, including the vibrations of the metal cluster. The electronic polarizabilities are to a good approximation additive and thus increase linearly with the number of $\mathrm{Ag}$ 
TABLE II: Isotropic polarizabilities $\alpha_{\text {iso }}$ (a.u.), HOMO-LUMO gaps $(\mathrm{eV})$, Raman cross sections for the $\omega_{4}=1583 \mathrm{~cm}^{-1}$ vibrational mode $\sigma_{4}\left(\mathrm{~cm}^{2}\right)$, integrated Raman scattering cross sections $\sigma_{\text {tot }}\left(\mathrm{cm}^{2}\right)$, and fractions $w(\%)$ of Raman scattering cross section from modes with frequencies larger than $200 \mathrm{~cm}^{-1}$ for benzenethiol $(\mathrm{PhSH})$ and $\mathrm{PhS}-\mathrm{Ag}_{n}$ complexes. The excitation wavelength is $2000 \mathrm{~nm}$.

\begin{tabular}{|l|c|c|c|c|c|}
\hline Complex & $\alpha_{\text {iso }}$ & $E_{\text {gap }}$ & $\sigma_{4} \dot{1} 0^{-33}$ & $\sigma_{\text {tot }}$ & $w$ \\
\hline $\mathrm{PhSH}$ & 85.8 & 5.96 & 1.39 & $3.34 \cdot 10^{-32}$ & 64.0 \\
$\mathrm{PhS}-\mathrm{Ag}_{1}$ & 130.7 & 3.35 & 16.50 & $1.53 \cdot 10^{-30}$ & 10.2 \\
$\mathrm{PhS}-\mathrm{Ag}_{6}$ & 351.7 & 1.53 & 1.63 & $2.16 \cdot 10^{-30}$ & 2.8 \\
$\mathrm{PhS}-\mathrm{Ag}_{7}(\mathrm{I})$ & 365.2 & 2.80 & 1.35 & $1.04 \cdot 10^{-30}$ & 2.7 \\
$\mathrm{PhS}-\mathrm{Ag}_{7}(\mathrm{II})$ & 374.9 & 2.54 & 0.64 & $1.23 \cdot 10^{-30}$ & 4.8 \\
$\mathrm{PhS}-\mathrm{Ag}_{8}$ & 425.6 & 1.34 & 0.48 & $1.67 \cdot 10^{-30}$ & 4.3 \\
$\mathrm{PhS}-\mathrm{Ag}_{9}$ & 478.2 & 2.09 & 7.98 & $1.35 \cdot 10^{-29}$ & 0.6 \\
$\mathrm{PhS}-\mathrm{Ag}_{10}$ & 529.3 & 1.22 & 14.43 & $2.28 \cdot 10^{-29}$ & 0.6 \\
$\mathrm{PhS}-\mathrm{Ag}_{11}$ & 568.8 & 1.95 & 1.00 & $1.81 \cdot 10^{-30}$ & 4.0 \\
\hline
\end{tabular}

atoms. The integrated Raman scattering cross sections of $\mathrm{PhS}-\mathrm{Ag}_{n}$ complexes are larger than that of benzenethiol by 2-3 orders of magnitude but do not increase monotonically with the cluster size $n$. Molecular vibrational modes contribute only a small fraction (less than $5 \%$ with the exception of $\mathrm{PhS}-\mathrm{Ag}$, see Tab. II) to the integrated Raman scattering cross section while the largest part of the scattered radiation arises from vibrations within the metal cluster.

Orientation effect. We find a significant dependence on the orientation of the benzene ring: the largest integrated Raman scattering cross sections are computed for the complexes $\mathrm{PhS}-\mathrm{Ag}_{n}, n=9,10$, in which the benzene ring points outward from the cluster surface, see Fig. 1. In contrast, in the $\mathrm{PhS}-\mathrm{Ag}_{n}, n=6-8,11$ complexes the aromatic ring is oriented towards the metal cluster and non-binding $\mathrm{C}-\mathrm{Ag}$ interactions reduce the integrated Raman scattering cross sections by about one order of magnitude. This orientation effect appears to be the major influence in the off-resonance Raman spectra of $\mathrm{PhS}-\mathrm{Ag}_{n}$ complexes, while the effect of increasing electronic polarizability and the characteristic alternation of HOMO-LUMO gaps in between even- and odd-numbered metal clusters $\mathrm{Ag}_{n}$ seem to be less important. The non-binding interactions of the benzene ring with the $\mathrm{Ag}_{n}$ cluster in the $\mathrm{PhS}_{-} \mathrm{Ag}_{n}, n=6-8,11$ complexes result in an efficient quenching of Raman scattering from metal cluster modes, increasing the relative weight of molecular vibrations.

Symmetry effect. The relative intensities of vibrational modes in Raman spectra of $\mathrm{PhS}_{-} \mathrm{Ag}_{n}$ complexes might be explained based on their symmetry and proximity to the $\mathrm{Ag}_{n}$ cluster. Comparison of the Raman spectra of the isomers $\mathrm{PhS}-\mathrm{Ag}_{7}$ (I) and $\mathrm{PhS}-\mathrm{Ag}_{7}$ (II) exemplifies the effect of the local symmetry of the benzene ring on the off-resonant enhancement. The $\mathrm{PhS}-\mathrm{Ag}_{7}$ (I) isomer is, similar to the isolated benzenethiol molecule, $C_{s}$-symmetric while the local symmetry of the benzene ring in the $\mathrm{PhS}_{-} \mathrm{Ag}_{7}$ (II) isomer is perturbed by unsymmetric bonding to the cluster. The symmetry of the benzene ring affects the aromatic $\mathrm{C}-\mathrm{C}$ stretching bands in the region of $1620-1660 \mathrm{~cm}^{-1}$. Only the totally symmetric aromatic $\mathrm{C}-\mathrm{C}$ stretching vibration $\left(\omega_{4}=1656 \mathrm{~cm}^{-1}\right.$ in benzenethiol, denoted as $8 a$ in Wilson's notation 61 ) is observed in the Raman spectra of $\mathrm{PhSH}$ and $\mathrm{PhS}-\mathrm{Ag}_{7}$ (I) while the corresponding non-totally symmetric vibration at lower frequency $\left(1641 \mathrm{~cm}^{-1}\right.$ in benzenethiol, $8 b$ in Wilson's notation) is at least one order of magnitude weaker and not observed in the experiment. The lower symmetry of the $\mathrm{PhS}_{-} \mathrm{Ag}{ }_{7}$ (II) manifests itself in the redistribution of Raman scattering cross sections among the aromatic $\mathrm{C}-\mathrm{C}$ stretching modes such that the lower-frequency $8 b$ mode gains intensity. As a consequence, a doublet of vibrational bands is formed in the aromatic $\mathrm{C}-\mathrm{C}$ stretching region. In the $\mathrm{PhS}-\mathrm{Ag}_{n}, n=9,10$, complexes, the interaction between the benzene ring and the $\mathrm{Ag}_{n}$ cluster is weak and local $C_{s}$ symmetry of the benzene ring is essentially unperturbed. This results in only one observable aromatic $\mathrm{C}-\mathrm{C}$ stretching band in the Raman spectra of these complexes.

Proximity effect. The proximity effect on the Raman scattering cross section may be observed in the region between 1000-1150 $\mathrm{cm}^{-1}$, including ring deformation modes at $\omega_{1}=1019 \mathrm{~cm}^{-1}$ and $\omega_{2}=1059 \mathrm{~cm}^{-1}$ and the $\mathrm{C}-\mathrm{S}$ stretching mode at $\omega_{3}=1136 \mathrm{~cm}^{-1}$ in benzenethiol, respectively. In both $\mathrm{PhS}-\mathrm{Ag}_{7}$ (I) and PhS-Ag $(\mathrm{II})$ clusters, the ring breathing mode at $1011-1015 \mathrm{~cm}^{-1}$ and the ring deformation mode at $1050-1055 \mathrm{~cm}^{-1}$ are strongly enhanced by the interaction with the $\mathrm{Ag}_{n}$ clusters. With benzene rings further away from the $\mathrm{Ag}_{n} \mathrm{clusters}$ in $\mathrm{PhS}_{-} \mathrm{Ag}_{n}$, $n=9,10$, enhancement of ring deformation modes is diminished in these clusters, while the $\mathrm{C}-\mathrm{S}$ stretching mode is more pronounced.

All three effects governing off-resonant surface enhancement of Raman response of $\mathrm{PhS}-\mathrm{Ag}_{n}$ complexes, namely the relative orientation of the benzene ring with respect to the cluster, the local symmetry of the benzene ring, and the proximity of the particular vibrational mode to the binding site, are interrelated. Their modulation by thermal 
large-amplitude motion of the aromatic ring may serve as a simple and plausible explanation for the "blinking" events observed in SERS experiments on 4-aminobenzenethiol attached to Au bowtie nanoantennas 27 or to molecular junctions $\underline{28}$

\section{Raman Excitation Profiles}

Raman excitation profiles of four strong totally symmetric benzenethiol vibrational modes, $\omega_{1}=1019 \mathrm{~cm}^{-1}$, $\omega_{2}=1059 \mathrm{~cm}^{-1}, \omega_{3}=1136 \mathrm{~cm}^{-1}$, and $\omega_{4}=1656 \mathrm{~cm}^{-1}$, were calculated for the excitation energy range $1.6-3.0 \mathrm{eV}$ $(413-775 \mathrm{~nm})$. These modes are dominant in experimental SERS spectra of benzenethiol. .2

In Figs. 4 and 5 we provide REPs and electronic excitation spectra of four different complexes $\mathrm{PhS}_{-} \mathrm{Ag}_{7}(\mathrm{I}), \mathrm{PhS}^{-}$ $\mathrm{Ag}_{7}$ (II), $\mathrm{PhS}-\mathrm{Ag}_{9}$, and $\mathrm{PhS}-\mathrm{Ag}_{10}$ in logarithmic scale. For comparison we also show REP of isolated benzenethiol averaged over all four modes. The simulated scattering cross sections for the vibrational modes $\omega_{1-4}$ in isolated benzenethiol differ by no more than a factor of two, therefore an averaged value of REP of benzenethiol (dashed line) is used to simplify the plots. The slope of the REP of benzenethiol is close to 4 and stems from the $\omega^{4}$ dependence of Raman scattering cross sections. $\underline{\underline{4}}$ The effect of intramolecular resonances is small in the studied range of excitation energies.

The isomers $\mathrm{PhS}-\mathrm{Ag}_{7}$ (I) and (II) in Fig. 4 represent two distinct bonding patterns (on-top and bridge), whereas the structure of the silver cluster remains essentially the same. The electronic excitation spectra of the complexes are quite dissimilar, which reflects the sensitivity of the electronic states to the binding pattern. For example, the lowest electronic excitation of the $\mathrm{PhS}-\mathrm{Ag}_{7}$ (II) complex is $0.2 \mathrm{eV}$ lower in energy than that of the $\mathrm{PhS}-\mathrm{Ag}_{7}$ (I) complex. All transitions within the excitation range $1.6-3.0 \mathrm{eV}$ are weak with oscillator strengths $10^{-1}-10^{-4}$.

Cluster-molecule resonant effect. The REPs illustrate the frequency dependence of SERS and allow for identification of two different contributions to chemical Raman enhancement. These are the baseline shifts of the REPs of the complexes compared to that of isolated benzenethiol and the additional modulation by resonance-type features. The baseline shift is attributed to the off-resonant enhancement discussed in the previous section while the resonances arise from electronic transitions between metal-molecular states. This is consistent with the conventional picture of chemical enhancement $\underline{\underline{21}}$ The off-resonant enhancement factor for both isomers of the $\mathrm{PhS}-\mathrm{Ag}_{7}$ complex is of the order of 1 and can be explained by the orientational effect discussed in the previous section.

The relative enhancement for different modes depends on the excitation energy. For example, the $\omega_{1}$ vibrational mode has the largest enhancement for the $\mathrm{PhS}-\mathrm{Ag}_{7}$ (I) complex in the energy range below the first electronic transition, whereas the $\omega_{3}$ becomes the strongest Raman mode above it. This observation is in accord with the empirical Tsuboi rule $\frac{63}{}$ : the lowest electronic excitation in the complex $\mathrm{PhS}-\mathrm{Ag}_{7}$ (I) involves the $\mathrm{Ag}-\mathrm{S}$ bond and has a larger impact on the $\mathrm{C}-\mathrm{S}$ stretching mode $\left(\omega_{3}\right)$.

The structures of the $\mathrm{PhS}-\mathrm{Ag}_{9}$ and $\mathrm{PhS}-\mathrm{Ag}_{10}$ complexes differ only by a single $\mathrm{Ag}$ atom, which is located approximately $4.8 \AA$ from the binding sites. The $\mathrm{PhS}-\mathrm{Ag}_{9}$ complex has a closed-shell electronic structure and shows a smaller number of electronic transitions as compared to the $\mathrm{PhS}-\mathrm{Ag}_{10}$. Both structures show 10-100 fold enhancements of Raman signals outside of resonant regions. Enhancement factors of different vibrational modes differ by about one order of magnitude. This can be seen by comparing the Raman cross sections of the complexes to that of isolated benzenethiol for the excitation energy $1.6 \mathrm{eV}$, Fig. 5 .

Most of electronic excitations shown in Figs. 4 and 5 result in resonance-type divergences of the REP. However, Raman enhancement in pre-resonant regions cannot be characterized by the oscillator strengths of the respective electronic transitions only. For instance, in the $\mathrm{PhS}-\mathrm{Ag}_{10}$ complex the electronic transition at $2.17 \mathrm{eV}$ has an oscillator strength 0.04, which is smaller than that of the $1.84 \mathrm{eV}$ transition (oscillator strength 0.05). Nevertheless, the former excitation induces a large peak in the REP, see Fig. 5 (b), while the latter has a much smaller effect. These two excitations differ by the degree to which $\mathrm{Ag}-\mathrm{S}$ bonds are affected by the electronic excitations, as can be seen in Fig. 6. The $2.17 \mathrm{eV}$ electronic excitation is localized around the bonding sites and does not involve all atoms in the $\mathrm{Ag}_{n}$ cluster, whereas the $1.84 \mathrm{eV}$ electronic excitation is delocalized. This observation lends support to the underlying assumption of this work that the effects of chemical bonding on surface enhancement can be modeled to a significant extent using finite-size metal clusters.

The occurrence of strong resonant Raman peaks is a common feature of all considered $\mathrm{PhS}-\mathrm{Ag}_{n}$ complexes. The strong peak in the REP of the $\mathrm{PhS}-\mathrm{Ag}_{7}$ (I) complex is centered around the $2.54 \mathrm{eV}$ electronic excitation, and in the $\mathrm{REP}$ of $\mathrm{PhS}-\mathrm{Ag}_{9}$ a similar feature can be associated with the region $2.8-3.0 \mathrm{eV}$.

Our approach does not include finite-lifetime effects and is thus not applicable in a strictly resonant case. The enhancement of a Raman signal at resonances scales inversely proportional to the fourth power of the homogeneous linewidth $\Gamma$ of the involved electronic states $\underline{\underline{20}}$ Since $\Gamma$ enters as a phenomenological parameter, estimates of the corresponding enhancement factors are inherently imprecise. To obtain lower-bound estimates of resonant enhancement factors we consider the Raman scattering cross section at frequencies $\Omega_{i} \pm \Gamma$, where $\Omega_{i}$ stand for electronic excitation 

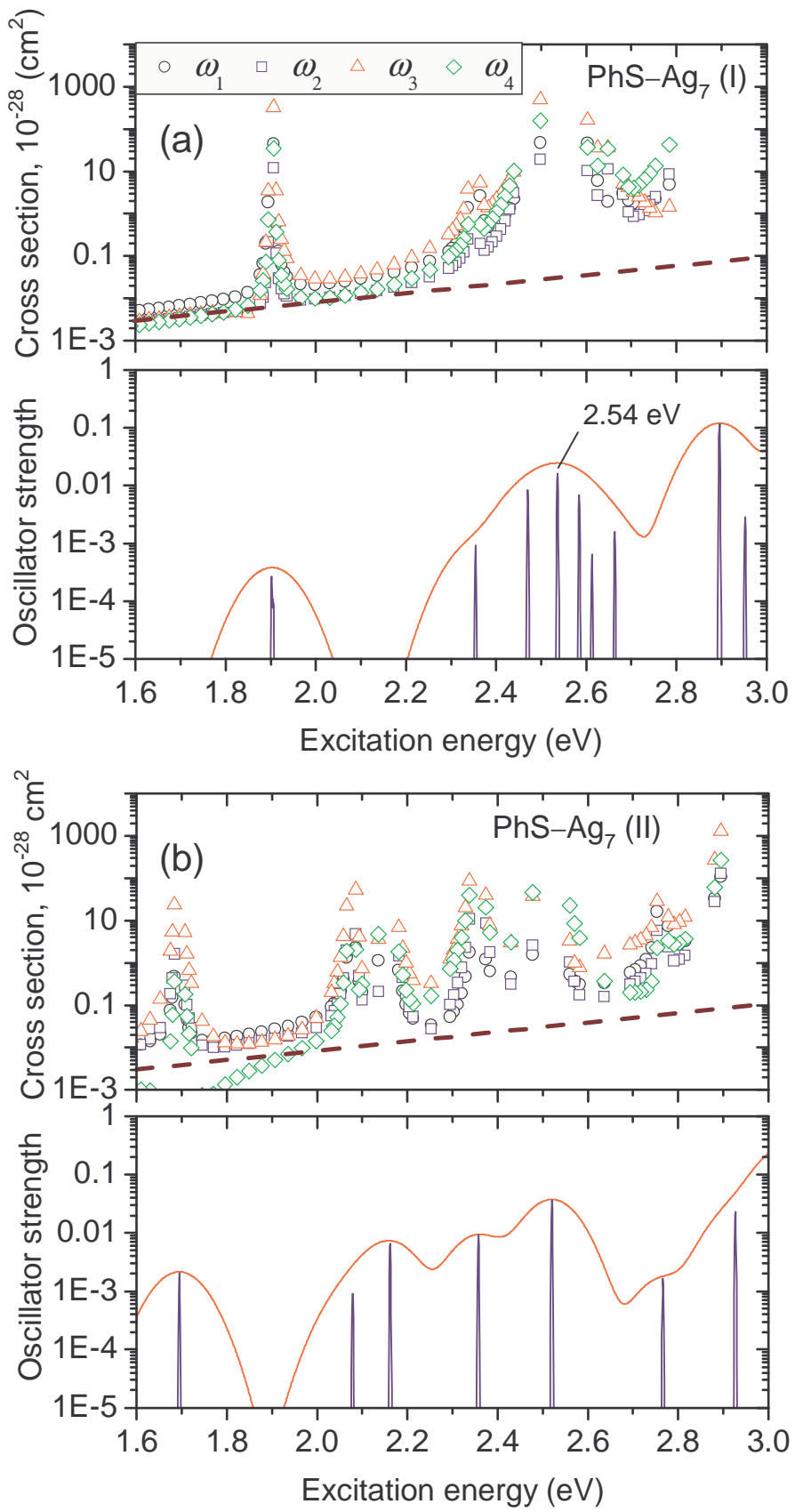

FIG. 4: The Raman excitation profiles (REPs) together with the electronic excitation spectra for (a) the $\mathrm{PhS}-\mathrm{Ag}_{7}(\mathrm{I})$ and (b) the $\mathrm{PhS}-\mathrm{Ag}_{7}$ (II) complexes. The vibrational modes are $\omega_{1}=1019 \mathrm{~cm}^{-1}, \omega_{2}=1059 \mathrm{~cm}^{-1}, \omega_{3}=1136 \mathrm{~cm}-1$, and $\omega_{4}=1656 \mathrm{~cm}^{-1}$. The dashed tilted line in the REPs plots corresponds to the response of isolated benzenethiol averaged over all four modes.

frequencies. For $\Gamma$ we use a pragmatic value $0.1 \mathrm{eV}$, which is consistent with Ref 24 . The estimated enhancement of Raman signal near the $2.17 \mathrm{eV}$ electronic transition in the $\mathrm{PhS}-\mathrm{Ag}_{10}$ complex is of the order of $10^{3}$ and varies about 10 times for different vibrational modes. Similar estimates are also obtained for other structures.

Usually, in SERS literature the enhancement below intramolecular excitations is associated with charge-transfer excitations that have very small oscillator strengths. For example, in Ref $\underline{24}$ electronic transitions at energies comparable to those considered here were found in a pyridine- $\mathrm{Ag}_{20}$ complex, with enhancements that were also about $10^{3}$. The excitations were referred to as charge-transfer states. In our system, all electronic transitions in the excitation range $1.6-3.0 \mathrm{eV}$ have a mixed metal-molecular character and can be associated with a partial charge transfer 

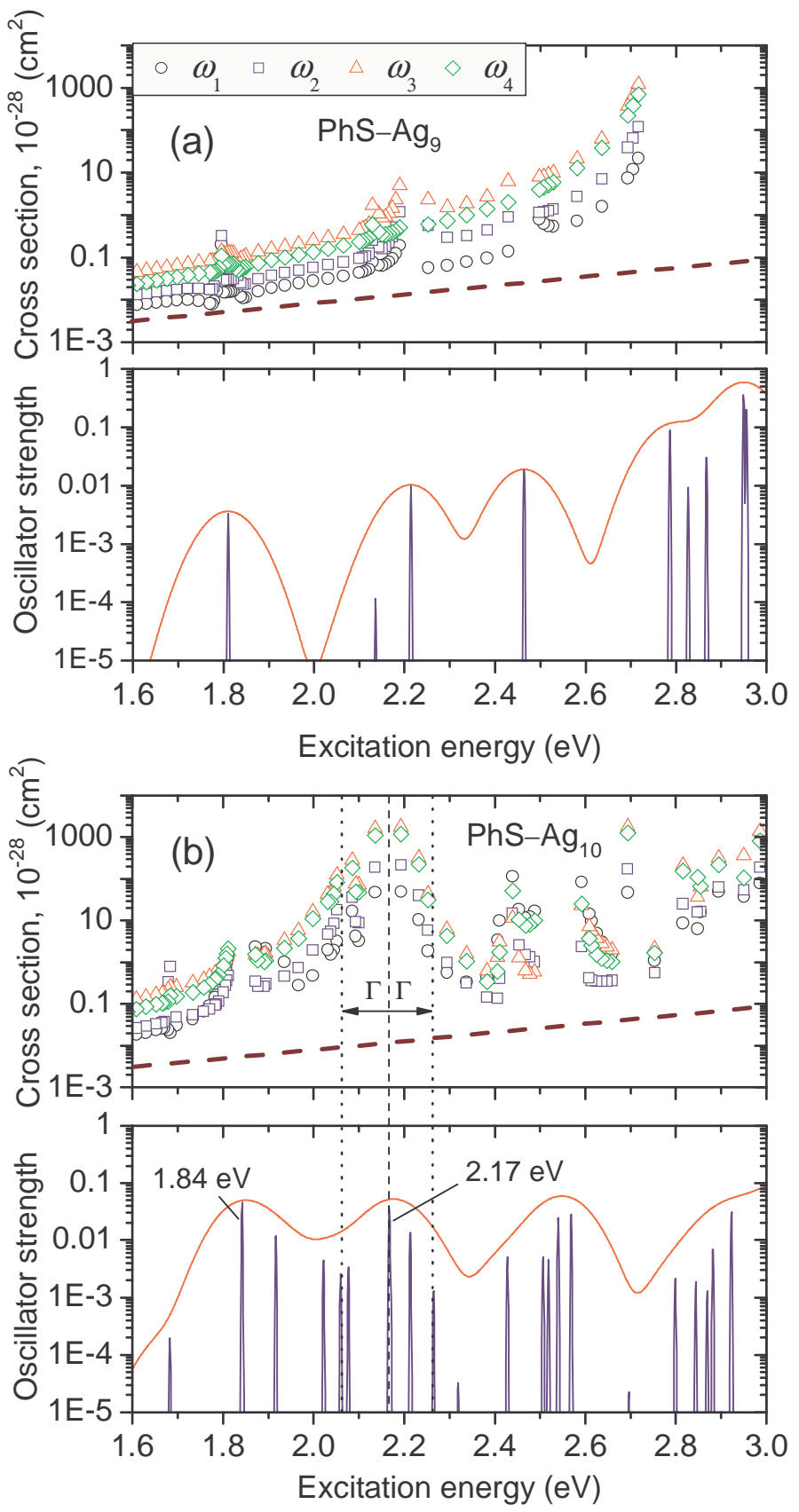

FIG. 5: The Raman excitation profiles together with the electronic excitation spectra for (a) the $\mathrm{PhS}-\mathrm{Ag} 9$ complex and (b) the PhS- $\mathrm{Ag}_{10}$ complex. The vibrational modes are $\omega_{1}=1019 \mathrm{~cm}^{-1}, \omega_{2}=1059 \mathrm{~cm}^{-1}, \omega_{3}=1136 \mathrm{~cm}^{-1}$, and $\omega_{4}=1656 \mathrm{~cm}^{-1}$. The dashed tilted line in the REPs plots corresponds to the response of isolated benzenethiol averaged over all four modes. $\Gamma=0.1 \mathrm{eV}$ is a phenomenological parameter characterizing homogeneous linewidth of electronic states.

between the cluster and the molecule. However, most of them have only a small contribution to the resonance Raman enhancement. Thus, besides narrow singularities, the computed cross sections are relatively smooth functions of the excitation energy. For example, the $1.9 \mathrm{eV}$ excitation in $\mathrm{PhS}-\mathrm{Ag}_{7}$ (I) complex, see Fig. 4, gives almost no enhancement of the Raman signal if we take into account the finite linewidth of the transition. The important excitations, such as the excitation shown in Fig. 6 (a)., are local to the binding site and are characterized by the change of the electron density around the binding sites only. It is important to notice that the difference in the static dipole between a ground and an excited state of the complexes for such transitions is rather small. For example, the change in the static dipole moment for the excitation of the $\mathrm{PhS}-\mathrm{Ag}_{10}$ complex depicted in Fig. 6 (a) is 3.7 Debye. 


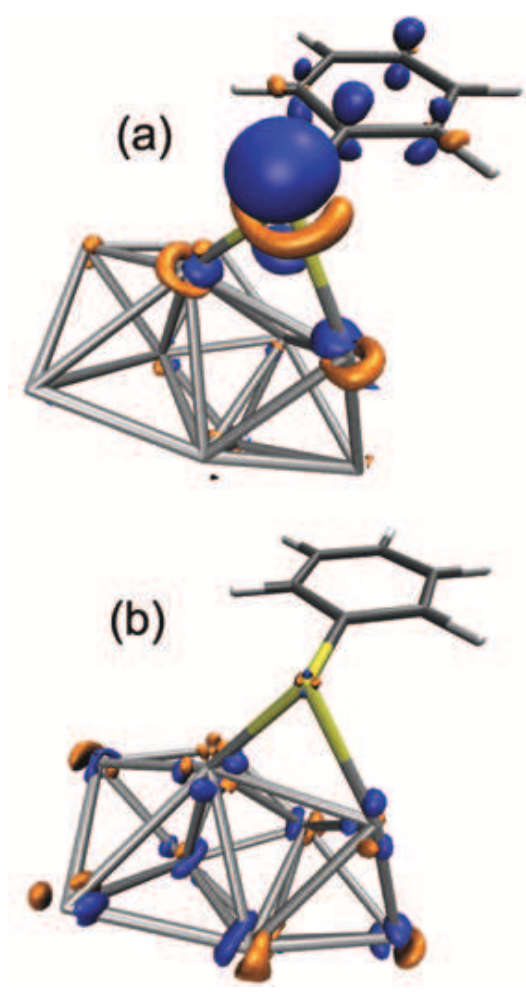

FIG. 6: The transition electron densities for (a) the $2.17 \mathrm{eV}$ electronic excitation and (b) the $1.84 \mathrm{eV}$ electronic excitation in the $\mathrm{PhS}-\mathrm{Ag}_{10}$ complex. The former transition results in the strong resonant features in the REP, whereas the latter one has much weaker effect. The light grey (orange) color corresponds to the transition density of -0.002 a.u., the dark grey (blue) corresponds to the transition density of 0.002 a.u.

\section{E. Discussion}

Many important features of experimental SERS results for benzenethiol ${ }^{1,2,3,32}$ are reflected in the computed Raman spectra of the $\mathrm{PhS}-\mathrm{Ag}_{n}$ complexes. The molecular vibrational frequencies of the complexes are shifted compared to that of isolated benzenethiol. The frequency shifts of intense $a^{\prime}$ modes of the complexes $\mathrm{PhS}-\mathrm{Ag}_{7}$ (I) and (II), $\mathrm{PhS}-\mathrm{Ag}_{9}$, and $\mathrm{PhS}-\mathrm{Ag}_{10}$ are compared to experimental SERS data in Tab. III The values and the signs of the computed shifts are in good agreement with the results of measurements. The magnitudes of the frequency shifts depend on the degree to which the $\mathrm{C}-\mathrm{S}$ bond is involved in the given vibration. For instance, the $\mathrm{C}-\mathrm{S}$ stretching mode $\omega_{3}^{\exp }=1094 \mathrm{~cm}^{-1}$ shows the largest shift on average, which is an additional manifestation of the proximity effect discussed in Sec. IIIC.

Comparisons of the computed Raman cross sections of the $\mathrm{PhS}-\mathrm{Ag}_{n}$ complexes to experimental SERS data should take into account that the chemisorbed molecules are no longer freely rotating. This has the effect that the orientational averaging of the Raman tensor depends on the shape of the metal substrate and the relative orientation of the adsorbed molecules. As a model, we consider benzenethiol molecules adsorbed on a spherical nanoparticle. The computed PhS$\mathrm{Ag}_{n}$ structures are oriented such that in the complexes with on-top binding, $n=6,7(\mathrm{I})$, the $\mathrm{Ag}-\mathrm{S}$ bond is orthogonal to the particle surface, and in the complexes with the bridge binding motif, $n=7$ (II), $8-11$ the plane formed by the two $\mathrm{Ag}-\mathrm{S}$ bonds is orthogonal to the particle surface. The Raman intensity of a vibrational mode with frequency $\omega_{n}$ is 64

$$
I\left(\omega_{n}, \omega_{\mathrm{ex}}\right) \propto\left(\omega_{\mathrm{ex}}-\omega_{n}\right)^{4}\left|g\left(\omega_{\mathrm{ex}}\right)\right|^{2}\left|g\left(\omega_{\mathrm{ex}}-\omega_{n}\right)\right|^{2} f\left(\alpha_{n}\left(\omega_{\mathrm{ex}}\right)\right),
$$

where $\omega_{\text {ex }}$ is the excitation frequency, and the electromagnetic enhancement factor is

$$
g(\omega)=\frac{\epsilon_{\mathrm{p}}(\omega)-\epsilon_{\mathrm{env}}}{\epsilon_{\mathrm{p}}(\omega)+2 \epsilon_{\mathrm{env}}} .
$$

$\epsilon_{\mathrm{p}}$ stands here for the dielectric constant of the metal particle and includes the plasmon resonance, and $\epsilon_{\mathrm{env}}$ is the dielectric constant of the environment, which is considered as not strongly frequency-dependent. $\alpha_{n}\left(\omega_{\mathrm{ex}}\right)$ denotes the 
TABLE III: Frequency shifts of benzenethiol Raman-active vibrational modes due to binding to the metal. The values of the vibrational frequencies are taken for neat benzenethiol from Ref. ${ }^{1}$. The shifts for the computed complexes, calculated as $\Delta \omega_{n}=\omega_{n}\left(\mathrm{PhS}-\mathrm{Ag}_{k}\right)-\omega_{n}(\mathrm{PhSH})$, are compared with the shifts of Raman lines, $\Delta \omega_{n}=\omega_{n}(\mathrm{SERS})-\omega_{n}(\mathrm{PhSH})$, from the

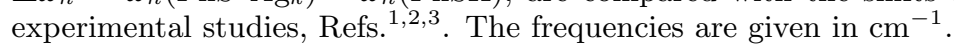

\begin{tabular}{|c|c|c|c|c|c|c|c|}
\hline Mode & $\omega_{1}$ & $\omega_{2}$ & $\omega_{3}$ & $\omega_{4}$ & $\omega_{5}$ & $\omega_{6}$ & $\omega_{7}$ \\
\hline Freq. $\mathrm{PhSH}$ & 1004 & 1027 & 1094 & 1583 & 414 & 701 & 918 \\
\hline $\mathrm{PhS}-\mathrm{Ag}_{7}(\mathrm{I})$ & -7 & -9 & -31 & -33 & 1 & 4 & -8 \\
\hline $\mathrm{PhS}-\mathrm{Ag}_{7}$ (II) & -4 & -5 & -24 & -17 & 3 & 6 & -12 \\
\hline $\mathrm{PhS}-\mathrm{Ag}_{9}$ & -1 & -2 & -18 & -8 & 6 & -4 & -5 \\
\hline $\mathrm{PhS}-\mathrm{Ag}_{10}$ & -1 & -3 & -18 & -9 & 5 & -4 & -11 \\
\hline Ref. ${ }^{1}$ & -1 & 0 & -18 & -7 & 8 & -6 & - \\
\hline $\operatorname{Ref}^{2}$ & 0 & 1 & -17 & -9 & 6 & -3 & - \\
\hline Ref $:^{-}$ & -1 & -2 & -21 & -11 & 5 & -8 & - \\
\hline
\end{tabular}

TABLE IV: Relative intensities of Raman lines, defined as $I\left(\omega_{n}\right) / I\left(\omega_{2}\right), \omega_{2}=1027 \mathrm{~cm}^{-1}$, are given for the $\mathrm{PhS}-\mathrm{Ag}_{n}, n=7,9,10$ complexes and for the experimental SERS spectra from Refs. ${ }_{1,2,3}$. The relative intensities for the complexes are computed using Eq. 5 assuming that electromagnetic enhancement is frequency independent, $g(\omega)=$ const. The mode $\omega_{7}=918 \mathrm{~cm}^{-1}$ is not observable in the SERS experiments. The excitation wavelength is $785 \mathrm{~nm}$. The vibrational frequencies of neat benzenethiol ${ }^{1}$ are given in $\mathrm{cm}^{-1}$.

\begin{tabular}{|c|c|c|c|c|c|c|}
\hline Mode & $\omega_{1}$ & $\omega_{3}$ & $\omega_{4}$ & $\omega_{5}$ & $\omega_{6}$ & $\omega_{7}$ \\
\hline Freq. $\mathrm{PhSH}$ & 1004 & 1094 & 1583 & 414 & 701 & 918 \\
\hline $\mathrm{PhS}-\mathrm{Ag}_{7}(\mathrm{I})$ & 1.2 & 1.4 & 2.7 & 0.4 & 0.5 & 1.0 \\
\hline $\mathrm{PhS}-\mathrm{Ag}_{7}$ (II) & 1.2 & 1.4 & 0.5 & 0.1 & 0.2 & 1.6 \\
\hline $\mathrm{PhS}-\mathrm{Ag}_{9}$ & 0.6 & 3.4 & 2.8 & 0.7 & 0.2 & 0.0 \\
\hline $\mathrm{PhS}-\mathrm{Ag}_{10}$ & 0.6 & 5.1 & 4.5 & 1.1 & 0.3 & 0.0 \\
\hline Ref. ${ }^{1}$ & 1.3 & 1.4 & 0.6 & 0.6 & 0.3 & - \\
\hline $\operatorname{Ref}^{2}$ & 1.4 & 1.3 & 1.3 & 1.0 & 0.4 & - \\
\hline Ref $:^{3}$ & 1.1 & 1.0 & 3.5 & 2.7 & 0.4 & - \\
\hline
\end{tabular}

Raman tensor of the mode $n$, and the orientational averaging function is given by

$$
f(\alpha)=4\left(\alpha_{11}^{2}+\alpha_{22}^{2}+16 \alpha_{33}^{2}\right)+\alpha_{11} \alpha_{22}+4 \alpha_{11} \alpha_{33}+4 \alpha_{22} \alpha_{33}+7\left(\alpha_{12}^{2}+4 \alpha_{13}^{2}+4 \alpha_{23}^{2}\right) .
$$

The orientational averaging used here ${ }^{64}$ is different from the isotropic averaging that has been utilized in the previous sections. Particularly convenient for comparison with experiment are relative Raman scattering cross sections which are defined as

$$
\frac{I\left(\omega_{n}, \omega_{\mathrm{ex}}\right)}{I\left(\omega_{\mathrm{ref}}, \omega_{\mathrm{ex}}\right)}=\frac{g^{2}\left(\omega_{\mathrm{ex}}-\omega_{n}\right)}{g^{2}\left(\omega_{\mathrm{ex}}-\omega_{\mathrm{ref}}\right)} \cdot \frac{\left(\omega_{\mathrm{ex}}-\omega_{n}\right)^{4} f\left(\alpha_{n}\right)}{\left(\omega_{\mathrm{ex}}-\omega_{\mathrm{ref}}\right)^{4} f\left(\alpha_{\mathrm{ref}}\right)},
$$

where $\omega_{\text {ref }}$ is a frequency of the reference vibrational mode. The first multiplier on the right-hand side of Eq. 5 represents the relative electromagnetic enhancement of the Raman scattering due to plasmon excitations in the metal particle. The chemical bonding of a molecule to a surface modifies the Raman tensor $\alpha$ and contributes to the second multiplier of Eq. 5 .

The computed relative intensities of several Raman lines for the complexes $\mathrm{PhS}-\mathrm{Ag}_{7}$ (I) and (II), $\mathrm{PhS}-\mathrm{Ag}_{9}$, and $\mathrm{PhS}-\mathrm{Ag}_{10}$ are compared to the experimental data in Tab. IV] Experimental SERS cross sections depend sensitively on the structure of the surface and the roughness features of the SERS substrate and are thus strongly influenced by the preparation technique, as illustrated by the differences between the experimental data in Tab. IV] Surface enhanced Raman spectra result from the appropriate averaging over the multitude of possible local bonding configurations. An additional important effect is due to differences in plasmonic resonance structures. Comparison of the experimental data with finite-size cluster models $\mathrm{PhS}-\mathrm{Ag}_{n}$ shows that indeed many experimental SERS features may be correlated with the models considered here. For example, all strong Raman lines observed in Ref $\mathrm{I}^{\underline{1}}$ belong to the $a^{\prime}$ representation, similar to the spectra of the $\mathrm{PhS}-\mathrm{Ag}_{9}$ and $\mathrm{PhS}-\mathrm{Ag}_{10}$ complexes. However, the relative intensities of the $\omega_{3}^{\exp }=$ 
TABLE V: Relative enhancement factors of molecular vibrational modes computed for the $\mathrm{PhS}-\mathrm{Ag}_{7}$ (I) and (II), $\mathrm{PhS}-\mathrm{Ag}_{9}$ and $\mathrm{PhS}-\mathrm{Ag}_{10}$ complexes using Eq. 6] as compared with the experimental data from Refs. ${ }^{32}$. The reference vibrational mode is $\omega_{1}^{\exp }($ SERS $)=1009 \mathrm{~cm}^{-1}$. The corresponding excitation wavelength $\lambda_{\text {ex }}$ is in $\mathrm{nm}$. To account for frequency dependence of electromagnetic enhancement the computed values were multiplied by $\left.g^{4}\left(\omega_{\mathrm{ex}}\right) / g^{4}\left(\omega_{\mathrm{ex}}\right)\right)$ estimated from the experiments. The vibrational frequencies in $\mathrm{cm}^{-1}$ are for benzenethiol on an Ag nanoparticle array from Ref..$^{32}$.

\begin{tabular}{|l|c|c|c|c|}
\hline Mode & $\omega_{1}$ & $\omega_{2}$ & $\omega_{3}$ & $\omega_{4}$ \\
\hline Freq. SERS & 1009 & 1027 & 1081 & 1575 \\
$\lambda_{\mathrm{ex}}$ & 705 & 703 & 700 & 692 \\
$g^{4}\left(\omega_{\mathrm{ex}}\right) / g^{4}\left(\omega_{\mathrm{ex}^{\prime}}\right)$ & 1.0 & 1.0 & 0.9 & 0.6 \\
\hline $\mathrm{PhS}-\mathrm{Ag}_{7}(\mathrm{I})$ & 1.0 & 0.8 & 1.0 & 1.4 \\
$\mathrm{PhS}-\mathrm{Ag}_{7}(\mathrm{II})$ & 1.0 & 0.6 & 1.0 & 0.1 \\
$\mathrm{PhS}-\mathrm{Ag}_{9}$ & 1.0 & 1.7 & 5.3 & 2.9 \\
$\mathrm{PhS}-\mathrm{Ag}_{10}$ & 1.0 & 1.7 & 7.8 & 4.6 \\
\hline Ref ${ }^{32}$ & 1 & - & 10 & 7 \\
\hline
\end{tabular}

$1094 \mathrm{~cm}^{-1}$ and $\omega_{4}^{\exp }=1583 \mathrm{~cm}^{-1}$ modes are too high as compared to the experimental data. The discrepancy stems from overestimation of the computed Raman intensities for isolated benzenethiol and also from a frequency dependence of electromagnetic enhancement, which is not accounted for in the model. For instance, in Ref $\underline{1}$ the excitation frequency is optimized to enhance modes about $1000 \mathrm{~cm}^{-1} \underline{65}$ Thus, the electromagnetic enhancement of the $\omega_{3}$ and $\omega_{4}$ modes is weaker as compared to the $1004 \mathrm{~cm}^{-1}$ mode. This trend should reduce the discrepancy between the experimental data of Ref. ${ }^{1}$ and the computed spectra of the $\mathrm{PhS}-\mathrm{Ag}_{9}$ and $\mathrm{PhS}-\mathrm{Ag}_{10}$ complexes. On the other hand, Refs $\stackrel{2}{2}$ and $\frac{3}{3}$ show some enhancement of the vibrational modes at $470 \mathrm{~cm}^{-1}$ and $960 \mathrm{~cm}^{-1}$, respectively, which belong to the $a^{\prime \prime}$ representation. A possible explanation is that molecular orientations on the metal surface have irregularities and also contain binding situations similar to $\mathrm{PhS}-\mathrm{Ag}_{7}$ (I) and (II), which show considerable enhancement for $a^{\prime \prime}$ modes. For instance, the relative intensity of the $960 \mathrm{~cm}^{-1}$ mode in $\mathrm{PhS}-\mathrm{Ag}_{7}$ (II) complex is 0.8 .

To get an additional verification of our model, relative enhancement factors for the $1094 \mathrm{~cm}^{-1}$ and $1583 \mathrm{~cm}^{-1}$ vibrational modes of the $\mathrm{PhS}-\mathrm{Ag}_{7}$ (I) and (II), $\mathrm{PhS}-\mathrm{Ag}_{9}$, and $\mathrm{PhS}-\mathrm{Ag}_{10}$ complexes have been compared to the enhancement factors measured in Ref ${ }^{32}$. A relative enhancement factor is defined for two vibrational modes $\omega_{n}$ and $\omega_{\text {ref }}$ with corresponding excitation frequencies $\omega_{\mathrm{ex}}$ and $\omega_{\mathrm{ex}^{\prime}}$ as

$$
\frac{\mathrm{EF}\left(\omega_{n}, \omega_{\mathrm{ex}}\right)}{\operatorname{EF}\left(\omega_{\mathrm{ref}}, \omega_{\mathrm{ex}^{\prime}}\right)}=\frac{g^{4}\left(\omega_{\mathrm{ex}}\right)}{g^{4}\left(\omega_{\mathrm{ex}}\right)}\left(\frac{f\left(\alpha_{n}\right)}{f_{\text {iso }}\left(\alpha_{n}\right)}\right) /\left(\frac{f\left(\alpha_{\mathrm{ref}}\right)}{f_{\text {iso }}\left(\alpha_{\mathrm{ref}}\right)}\right)
$$

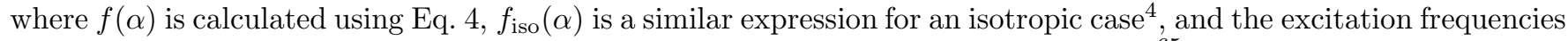
have been chosen to get a maximal enhancement of corresponding vibrational modes $\underline{65}$ Near a plasmonic resonance the first multiplier on the right hand side of Eq. 6 can be approximated by the ratio of the extinction coefficients of the plasmonic structure. The computed relative enhancement factors for the $\omega_{3}$ and $\omega_{4}$ modes of $\mathrm{PhS}-\mathrm{Ag}_{n}, n=9,10$, complex given in Tab. $\mathrm{V}$ agree well with the experimental data from Ref ${ }^{32}$.

Resonant structure of Raman cross sections discussed in Sec. IIID is hardly observable in experiments of Refs. $1,2,3,32$, where Raman scattering is measured for an inhomogeneous ensemble of molecules with their local environment. However, it can be observed in single molecule experiments. For example, the fine structure of single-molecule REPs measured in Ref $\frac{15}{n}$ may be interpreted as a result of resonances with mixed metal-molecular states.

\section{CONCLUSIONS}

We have analyzed the Raman response of benzenethiol chemisorbed on small silver clusters and find overall enhancement of the response of the order of $10^{3}$ as compared to isolated benznethiol. Mixed metal-molecular electronic states are formed due to chemical bonding. Raman response from the metal-molecular complexes exhibits resonance-type features even in the range far below the onset of molecular electronic excitations. We identify several mechanisms contributing to enhancement of Raman scattering in both off-resonant and resonant regimes. These include the relative orientation of the benzene ring with respect to the cluster, the local symmetry of the benzene ring, and the proximity of the particular vibrational mode to the binding site. Additional enhancement of Raman response by several orders of magnitude arises from resonant excitations localized around the binding sites, whereas response from other excitations in this range is significantly weaker. Specific properties of Raman response are strongly dependent on the local 
atomic environment of adsorbate. However, important features in SERS of benzenethiol on silver surfaces such as vibrational frequency shifts and relative enhancement factors may be explained using finite-size cluster models. Since the atomic structure of SERS substrates cannot currently be controlled in experiments the described effects should be averaged over a set of possible binding patterns. Nevertheless, our results might provide a guidance for optimization of SERS-active structures and are useful for interpretation of single molecule SERS measurements.

\section{ACKNOWLEDGMENTS}

We thank Roshan Aggarwal for providing the experimental data and the text of the manuscript before its publication. We also much appreciate Eric Diebold and Mohamad Banaee for useful discussions. This work was supported by the Defense Advanced Research Project Agency under Contract No FA9550-08-1-0285. R. O.-A. was supported by CONACyT and Fundación México en Harvard A.C. We thank the High Performance Technical Computing Center at the Faculty of Arts and Sciences of Harvard University and the National Nanotechnology Infrastructure Network Computation project for invaluable support.

* saykin@fas.harvard.edu

$\dagger$ aspuru@chemistry.harvard.edu

1 M. Moskovits, Rev. Mod. Phys., 1985, 57, 783.

2 A. Otto, I. Mrozek, H. Grabhorn and W. Akemann, J. Phys.: Condens. Matter, 1992, 4, 1143.

3 T. Vosgröne and A. J. Meixner, ChemPhysChem, 2005, 6, 154.

4 S. Nie and S. R. Emory, Science, 1997, 275, 1102.

${ }^{5}$ K. Kneipp, Y. Wang, H. Kneipp, L. T. Perelman, I. Itzkan, R. R. Dasari and M. S. Feld, Phys. Rev. Lett., $1997,78,1667$.

${ }^{6}$ V. M. Zamarion, R. A. Timm, K. Araki and H. E. Toma, Inorg. Chem., 2008, 47, 2934.

7 X. Zhang, N. C. Shah and R. P. Van Duyne, Vib. Spectrosc., 2006, 42, 2.

8 J. N. Anker, W. P. Hall, O. Lyandres, N. C. Shah, J. Zhao and R. P. Van Duyne, Nat. Mater., $2008,7,442$.

9 Y. Chu, E. Schonbrun, T. Yang and K. B. Crozier, Appl. Phys. Lett., 2008, 93, 181108.

${ }^{10}$ M. D. Austin, H. Ge, W. Wu, M. Li, Z. Yu, D. Wasserman, S. A. Lyon and S. Y. Chou, Appl. Phys. Lett., $2004,84,5299$.

11 J. P. Camden, J. Dieringer, J. Zhao and R. P. Van Duyne, Acc. Chem. Res., 2008, 41, 1653.

12 A. Gopinath, S. V. Boriskina, B. M. Reinhard, L. Dal Negro, Optics Express, 2009, 17, 3741.

13 E. D. Diebold, N. H. Mack, S. K. Doorn and E. Mazur, Langmuir, 2009, 25, 1790.

14 There is a controversy in the definition of the enhancement factor discussed recently in E. C. Le Ru, E. Blackie, M. Meyer and P. G. Etchegoin, J. Phys. Chem. C, 2007, 111, 13794.

15 J. A. Dieringer, K. L. Wustholz, D. J. Masiello, J. P. Camden, S. L. Kleinman, G. C. Schatz and R. P Van Duyne, J. Am. Chem. Soc., 2009, 131, 849.

16 A. Otto, J. Raman Spectrosc., 2005, 36, 497.

17 R. M. Lazorenko-Manevich, Russ. J. Electrochem., 2005, 41, 799.

18 B. N. J. Persson, Chem. Phys. Lett., 1981, 82, 561.

19 F. J. Adrian, J. Chem. Phys., 1982, 77, 5302.

20 J. R. Lombardi, R. L. Birke, T. Lu and J. Xu, J. Chem. Phys., 1986, 84, 4174.

21 L. Jensen, C. M. Aikens and G. C. Schatz, Chem. Soc. Rev., 2008, 37, 1061.

${ }^{22}$ R. F. Aroca, R. E. Clavijo, M. D. Halls and H. B. Schlegel, J. Phys. Chem. A, 2000, 104, 9500.

${ }^{23}$ L. Jensen, L. L. Zhao, J. Autschbach and G. C. Schatz, J. Chem. Phys., 2005, 123, 174110.

${ }^{24}$ L. Zhao, L. Jensen and G. C. Schatz, J. Am. Chem. Soc., 2006, 128, 2911.

25 L. Jensen, L. L. Zhao and G. C. Schatz, J. Phys. Chem. C, 2007, 111, 4756.

26 S. M. Morton and L. Jensen, J. Am. Chem. Soc., 2009, 131, 4090.

27 D. P. Fromm, A. Sundaramurthy, A. Kinkhabwala, P. J. Schuck, G. S. Kino and W. E. Moerner, J. Chem. Phys., 2006 124, 061101.

${ }^{28}$ D. R. Ward, N. J. Halas, J. W. Ciszek, J. M. Tour, Y. Wu, P. Nordlander and D. Natelson, Nano Lett., $2008,8,919$.

1 K. B. Biggs, J. P. Camden, J. N. Anker, and R. P. Van Duyne, J. Phys. Chem. A, 2009, 113, 4581.

${ }^{2}$ K. T. Carron and L. G. Hurley, J. Phys. Chem., 1991, 95, 9979. It should be noticed that the vibrational modes of neat benzenethiol are assigned incorrectly in Table I of the reference. For the correct assignement see Ref ${ }^{60}$.

3 R. L. Aggarwal, L. W. Farrar, E. D. Diebold and D. L. Polla, J. Raman Spectrosc., 2009, DOI:10.1002/jrs.2396.

32 A. D. McFarland, M. A. Young, J. A. Dieringer and R. P. Van Duyne, J. Phys. Chem. B, 2005, $109,11279$.

33 D. Rappoport and F. Furche, J. Chem. Phys, 2007, 126, 201104.

${ }^{34}$ R. Ahlrichs, M. Bär, M. Häser, H. Horn and C. Kölmel, Chem. Phys. Lett., 1989, 162, 165. For current version see http://www.turbomole.com

${ }^{35}$ F. Weigend and R. Ahlrichs, Phys. Chem. Chem. Phys, 2005, 7, 3297.

36 A. Schäfer, H. Horn and R. Ahlrichs, J. Chem. Phys., 1992, 97, 2571. 
37 D. Andrae, U. Häußermann, M. Dolg, H. Stoll and H. Preuß, Theor. Chim. Acta, 1990, 77, 123.

38 J. P. Perdew, M. Ernzerhof and K. Burke, J. Chem. Phys., 1996, 105, 9982.

39 C. Van Caillie and R. D. Amos, Chem. Phys. Lett., 2000, 328, 446.

40 C. Van Caillie and R. D. Amos, Phys. Chem. Chem. Phys., 2000, 2, 2123.

41 M. Harb, F. Rabilloud, D. Simon, A. Rydlo, S. Lecoultre, F. Conus, V. Rodrigues and C. Félix, J. Chem. Phys., 2008, 129, 194108.

${ }^{42}$ K. Baishya, J. C. Idrobo, S. Öğ̈ü, M. Yang, K. Jackson and J. Jellinek, Phys. Rev. B, 2008, 78, 075439.

43 M. Marsman, J. Paier, A. Stroppa and G. Kresse, J. Phys.: Condens. Matter, 2008, 20, 064201.

44 N. T. Maitra, J. Chem. Phys., 2005, 122, 234104.

45 M. J. G. Peach, T. Helgaker, P. Sałek, T. W. Keal, O. B. Lutnæs, D. J. Tozer and N. C. Handy, Phys. Chem. Chem. Phys., $2006,8,558$.

${ }^{46}$ Q. Wu and T. Van Voorhis, J. Chem. Theory Comput., 2006, 2, 765.

47 J. P. Perdew, V. N. Staroverov, J. Tao and G. E. Scuseria, Phys. Rev. A, 2008, 78, 052513.

48 P. Deglmann, F. Furche and R. Ahlrichs, Chem. Phys. Lett., 2002, 362, 511.

49 J. C. Idrobo, S. Ögüut and J. Jellinek, Phys. Rev. B, 2005, 72, 085445.

50 J. C. Idrobo, S. Öğüt, J. Jellinek and R. Ferrando, Phys. Rev. B, 2007, 75, 233411.

51 M. E. Casida, in Recent Advances in Density Functional Methods, Part I, edited by D. P. Chong, World Scientific, Singapore, 1995, p. 155-192.

52 R. Bauernschmitt and R. Ahlrichs, Chem. Phys. Lett., 1996, 256, 454.

53 F. Furche and D. Rappoport, in Computational Photochemistry, edited by M. Olivucci, Elsevier, Amsterdam, 2005, pp. 93-128.

${ }^{54}$ C. D. Bain, E. B. Troughton, Y. T. Tao, J. Evall and G. M. Whitesides, R. G. Nuzzo, J. Am. Chem. Soc., $1989,111,321$.

55 D. M. Jaffey and R. J. Madix, J. Am. Chem. Soc., 1994, 116, 3020.

56 J. Nara, S. Higai, Y. Morikawa, T. Ohno, J. Chem. Phys., 2004, 120, 6705.

${ }^{57}$ The basis set superposition error of a pyridine molecule attached to an $\mathrm{Ag}_{20}$ to be ca. $0.7 \mathrm{kcal} / \mathrm{mol}^{24}$.

58 C. M. Whelan, C. J. Barnes, C. G. H. Walker, N. M. D. Brown, Surf. Sci., 1999, 425, 195.

59 A. Schweig, F. Diehl, K. Kesper and H. Meyer, J. Molec. Struct., 1989, 198, 307.

60 J. H. S. Green, Spectrochim. Acta, 1962, 18, 39.

61 E. B. Wilson, Jr., Phys. Rev., 1934, 45, 706

4 D. A. Long, The Raman Effect, Wiley, Chichester, 2002.

63 A. Y. Hirakawa and M. Tsuboi, Science, 1975, 188, 359.

64 J. A. Creighton Surf. Sci., 1983, 124, 209.

${ }^{65}$ The enhancement factor for a given mode $\omega_{n}$ is maximal if $\omega_{\mathrm{ex}}-\omega_{\mathrm{pl}} \approx \omega_{n} / 2$, where $\omega_{\mathrm{pl}}$ is the frequency of a plasmonic resonance ${ }^{32}$ At this condition $g\left(\omega_{\mathrm{ex}}-\omega_{n}\right)=g\left(\omega_{\mathrm{ex}}\right)$. 


\section{SUPPLEMENTARY INFORMATION}

\section{A. Electronic Excitation Spectra}

The absorption spectra of the simulated $\mathrm{Ag}_{n}$ clusters and $\mathrm{PhS}-\mathrm{Ag}_{n}$ complexes, $n=6,8-11$ are shown in Figs. 7 and 8 . For $n=6$, the structure of the silver cluster in the $\mathrm{PhS}-\mathrm{Ag}_{n}$ complex differs from the one of the bare silver cluster because of the cluster reconstruction. This is discussed in Sec. 3.1 of the manuscript in more details.

\section{B. Off-resonance Raman Spectra}

The relative intensities of the computed Raman lines of isolated benzenethiol as compared to the relative Raman intensities measured for neat benzenethiol $\mathbb{1}^{1,2,3}$ are given in Tab. VI] The intensities are in good agreement except of the $\omega_{1}^{\exp }=1004 \mathrm{~cm}^{-1}$ vibrational mode. Changing the exchange functional in DFT simulations results in minor improvements only.

The Raman spectra of $\mathrm{PhS}-\mathrm{Ag}_{n}$ complexes, $n=1,6,8,11$ computed at the excitation energy $0.62 \mathrm{eV}(2000 \mathrm{~nm}$ excitation wavelength) are shown in Fig. 9. The excitation energy used is below the lowest electronic transition in the structures. The complex $\mathrm{PhS}-\mathrm{Ag}$ shows a strong enhancement of totally symmetric vibrational modes, while in the other complexes, the non-bonding interaction between the aromatic ring and the cluster results in a suppression of the integrated Raman scattering cross section and a redistribution of intensities between the totally symmetric and non-totally symmetric modes. See Sec. 3.2 of the manuscript.

\section{Raman Excitation Profiles}

The Raman excitation profiles (REPs) and low-frequency electron excitation spectra for $\mathrm{PhSH}$ and $\mathrm{PhS}-\mathrm{Ag}_{n}$ complexes, $n=1,6,8,11$ for the computed vibrational modes, $\omega_{1}=1019 \mathrm{~cm}^{-1}, \omega_{2}=1059 \mathrm{~cm}^{-1}, \omega_{3}=1136 \mathrm{~cm}^{-1}$, and $\omega_{4}=1656 \mathrm{~cm}^{-1}$, are shown in Figs. 10][14. The range of excitation energies is $1.6-3.0 \mathrm{eV}$. In logarithmic scale the REPs for isolated PhSH, Fig. 10] are almost linear in the excitation energy, which is consistent with the semiclassical

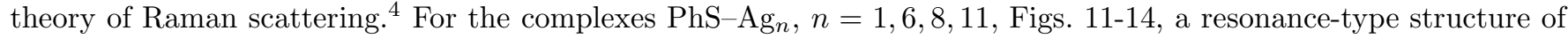
REPs originates in the electronic excitations to mixed metal-molecular states.

\section{Discussions}

The frequency shifts of four totally symmetric vibrational modes $\omega_{1}=1019 \mathrm{~cm}^{-1}, \omega_{2}=1059 \mathrm{~cm}^{-1}, \omega_{3}=1136 \mathrm{~cm}^{-1}$, and $\omega_{4}=1656 \mathrm{~cm}^{-1}$ in $\mathrm{PhS}-\mathrm{Ag}_{n}, n=1,6-11$ complexes are collected in Tab. VII On average, the values of the shifts are larger for the complexes where total Raman scattering is quenched, $\mathrm{PhS}-\mathrm{Ag}_{n}, n=6,7,8,11$.

* saykin@fas.harvard.edu

† aspuru@chemistry.harvard.edu

1 K. B. Biggs, J. P. Camden, J. N. Anker, and R. P. Van Duyne, J. Phys. Chem. A, 2009, 113, 4581.

${ }^{2}$ K. T. Carron and L. G. Hurley, J. Phys. Chem., 1991, 95, 9979.

3 R. L. Aggarwal, L. W. Farrar, E. D. Diebold and D. L. Polla, J. Raman Spectrosc., 2009, DOI:10.1002/jrs.2396.

${ }^{4}$ D. A. Long, The Raman Effect, Wiley, Chichester, 2002. 
TABLE VI: The relative intensities of the computed Raman lines for isolated benzenethiol as compared to the experimental data for neat benzenethiol, Refs. 1, 2,3. The relative intensities are defined with respect to the $1027 \mathrm{~cm}^{-1}$ vibrational mode. The excitation wavelength is $785 \mathrm{~nm}$. The frequencies are in $\mathrm{cm}^{-1}$.

\begin{tabular}{|l|c|c|c|c|c|c|}
\hline Mode & $\omega_{1}$ & $\omega_{3}$ & $\omega_{4}$ & $\omega_{5}$ & $\omega_{6}$ & $\omega_{7}$ \\
\hline Freq. PhSH & 1004 & 1094 & 1583 & 414 & 701 & 918 \\
\hline PhSH $^{\text {comp }}$ & 1.0 & 1.0 & 0.9 & 0.5 & 0.3 & 0.4 \\
PhSH $^{\text {exp Ref. } 1} \underline{1}$ & 3.0 & 0.5 & 0.3 & 0.7 & 0.7 & 0.3 \\
PhSH $^{\exp }$ Ref. 2 & 4.5 & 0.4 & 0.4 & 0.6 & 0.7 & 0.2 \\
PhSH $^{\text {exp }}$ Ref. & 2.9 & 0.6 & 1.0 & 1.0 & 0.5 & 0.4 \\
\hline
\end{tabular}

TABLE VII: The relative shifts of four totally symmetric vibrational modes in $\mathrm{PhS}-\mathrm{Ag}_{n}, n=1,6-11$, complexes as compared to the unperturbed frequencies in isolated benzenethiol, $\Delta \omega_{n}=\omega_{n}\left(\mathrm{PhS}-\mathrm{Ag}_{k}\right)-\omega_{n}(\mathrm{PhSH})$. The computed frequencies for isolated benzenethiol are $\omega_{1}=1019 \mathrm{~cm}^{-1}, \omega_{2}=1059 \mathrm{~cm}^{-1}, \omega_{3}=1136 \mathrm{~cm}^{-1}$, and $\omega_{4}=1656 \mathrm{~cm}^{-1}$. The values of the shifts are given in $\mathrm{cm}^{-1}$.

\begin{tabular}{|l|c|c|c|c|}
\hline Complex & $\Delta \omega_{1}$ & $\Delta \omega_{2}$ & $\Delta \omega_{3}$ & $\Delta \omega_{4}$ \\
\hline $\mathrm{PhS}-\mathrm{Ag}_{1}$ & -0 & -4 & -21 & -10 \\
$\mathrm{PhS}-\mathrm{Ag}_{6}$ & -7 & -8 & -26 & -28 \\
$\mathrm{PhS}-\mathrm{Ag}_{7}(\mathrm{I})$ & -7 & -9 & -31 & -33 \\
$\mathrm{PhS}-\mathrm{Ag}_{7}(\mathrm{II})$ & -4 & -5 & -24 & -17 \\
$\mathrm{PhS}-\mathrm{Ag}_{8}$ & -5 & -5 & -29 & -16 \\
$\mathrm{PhS}-\mathrm{Ag}_{9}$ & -1 & -2 & -18 & -8 \\
$\mathrm{PhS}-\mathrm{Ag}_{10}$ & -1 & -3 & -18 & -9 \\
$\mathrm{PhS}-\mathrm{Ag}_{11}$ & -6 & -6 & -28 & -19 \\
\hline
\end{tabular}




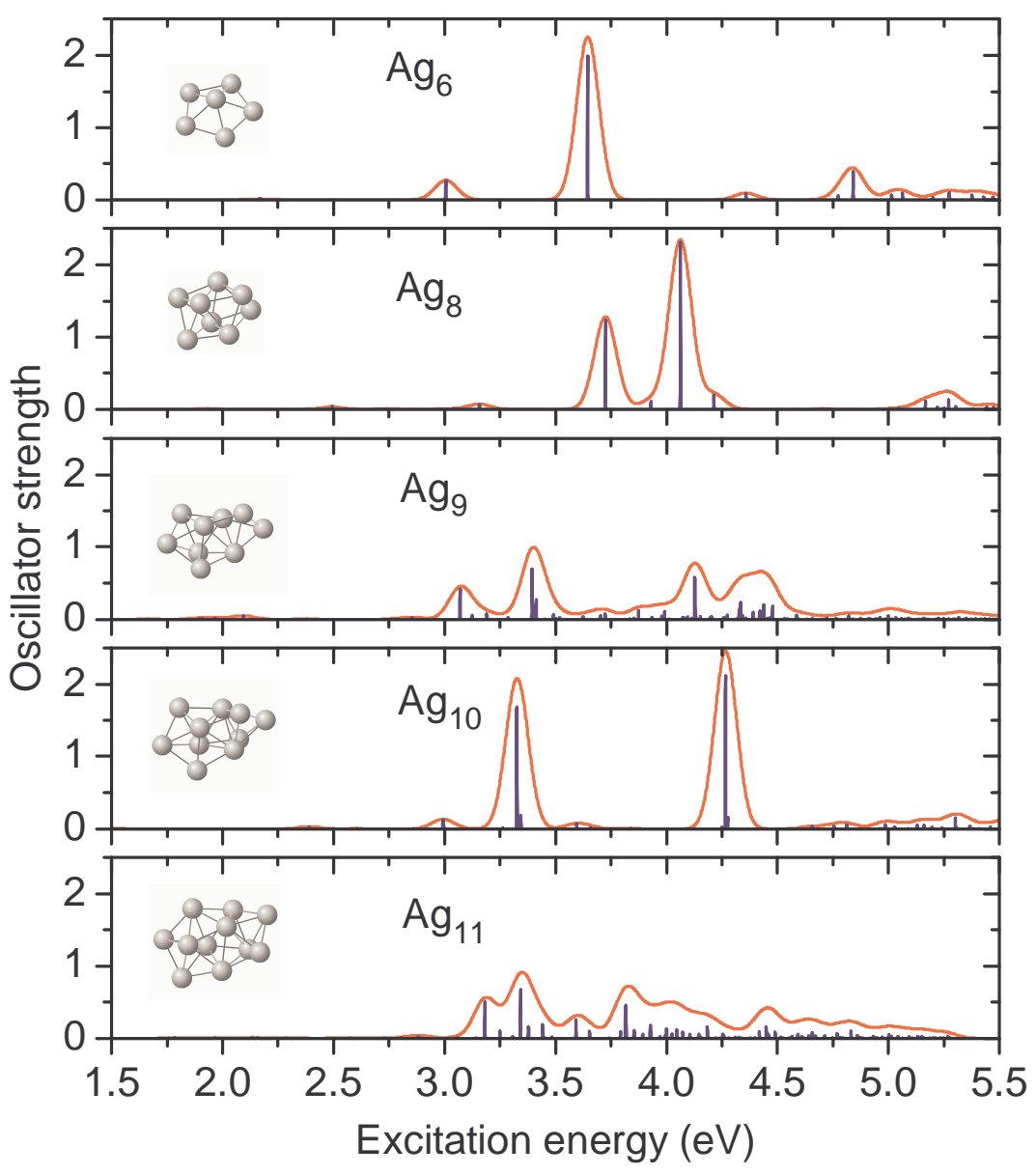

FIG. 7: Absorption spectra of the computed $\operatorname{Ag}_{n}$ clusters, $n=6,8-11$. 


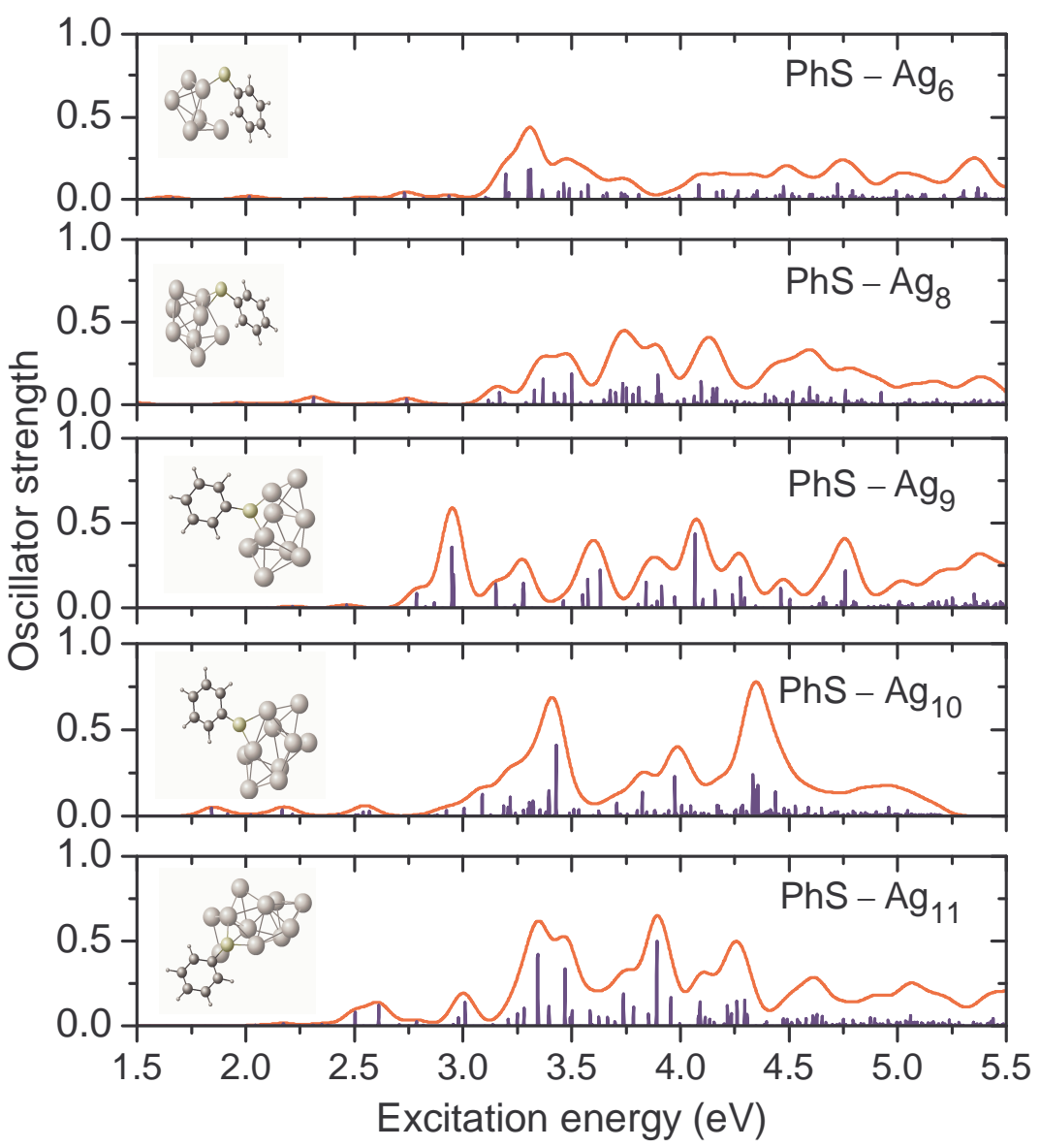

FIG. 8: Absorption spectra of the computed $\mathrm{PhS}-\mathrm{Ag}_{n}$ complexes, $n=6,8-11$. 

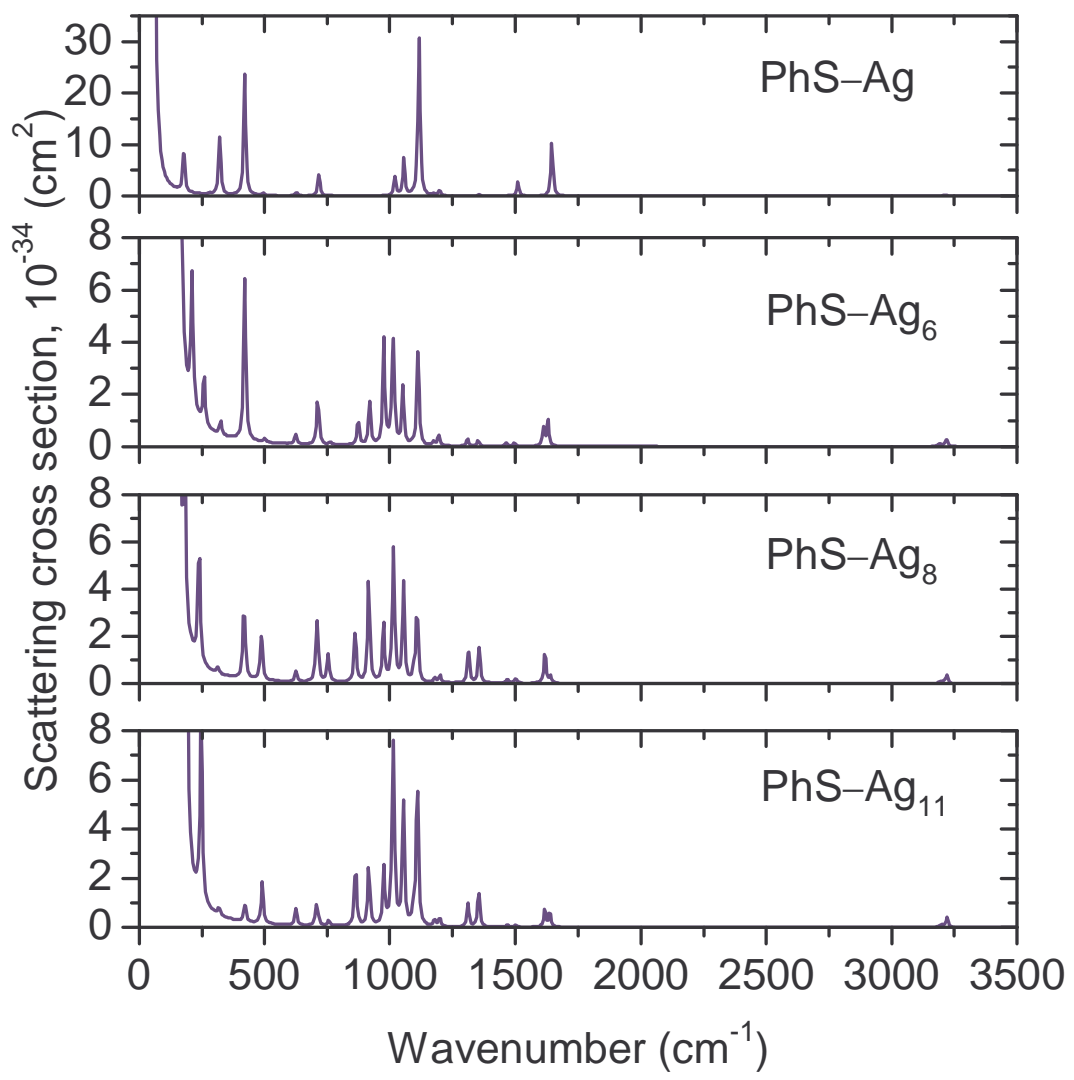

FIG. 9: Off-resonance Raman spectra of the computed $\mathrm{PhS}-\mathrm{Ag}_{n}$ complexes, $n=1,6,8,11$. The excitation energy is 0.62 eV, which corresponds to $2000 \mathrm{~nm}$ wavelength. 


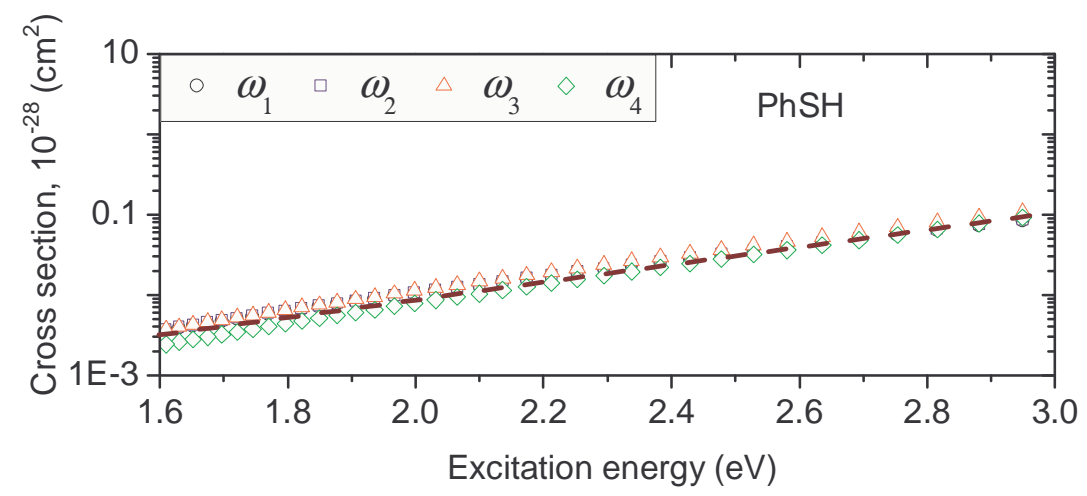

FIG. 10: Raman excitation profile for the vibrational modes $\omega_{1}=1019 \mathrm{~cm}^{-1}, \omega_{2}=1059 \mathrm{~cm}^{-1}, \omega_{3}=1136 \mathrm{~cm}^{-1}$, and $\omega_{4}=1656 \mathrm{~cm}^{-1}$ in isolated benzenethiol. 


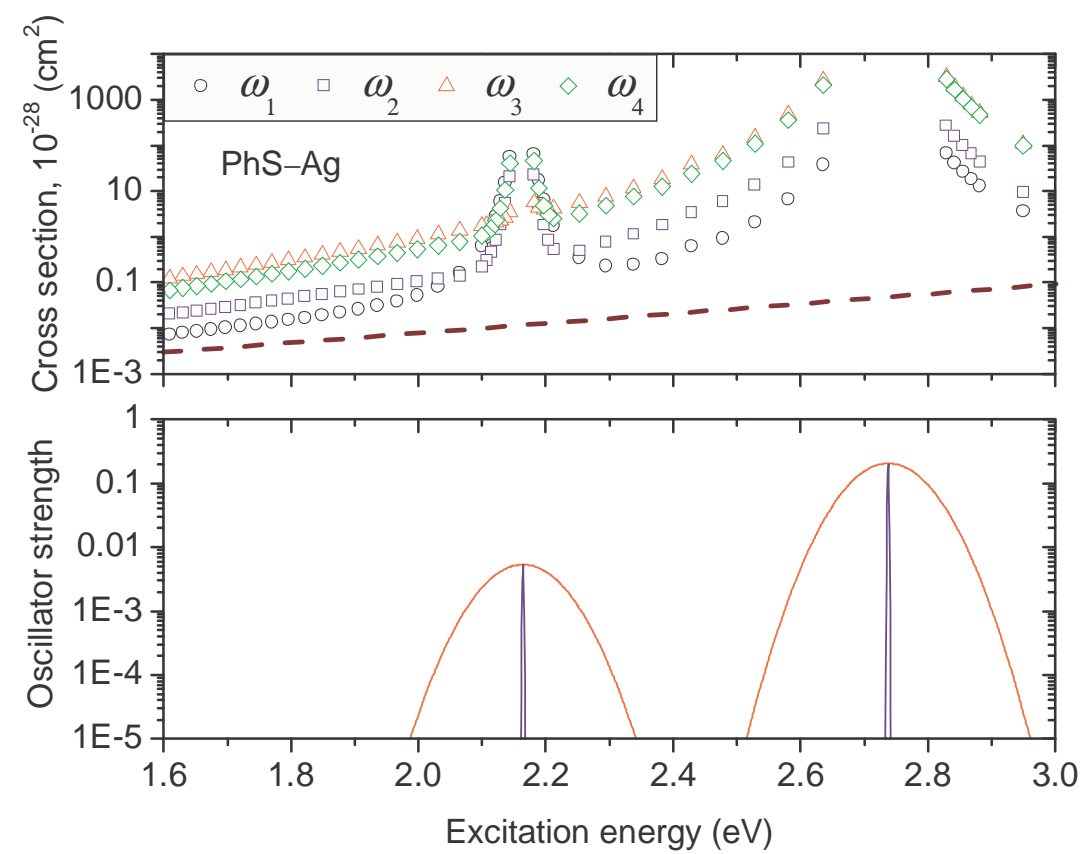

FIG. 11: Raman excitation profile for the vibrational modes $\omega_{1}=1019 \mathrm{~cm}^{-1}, \omega_{2}=1059 \mathrm{~cm}^{-1}, \omega_{3}=1136 \mathrm{~cm}^{-1}$, and $\omega_{4}=1656 \mathrm{~cm}^{-1}$ in the $\mathrm{PhS}-\mathrm{Ag}$ complex. 


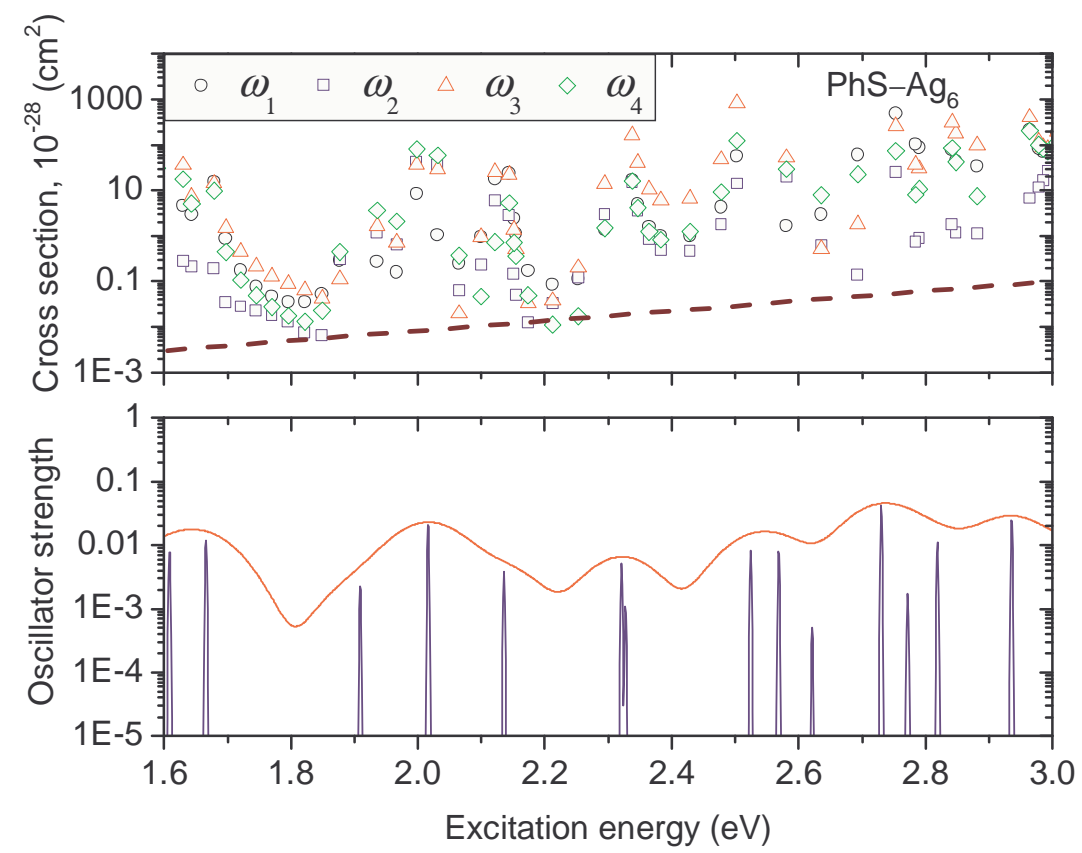

FIG. 12: Raman excitation profile for the vibrational modes $\omega_{1}=1019 \mathrm{~cm}^{-1}, \omega_{2}=1059 \mathrm{~cm}^{-1}, \omega_{3}=1136 \mathrm{~cm}^{-1}$, and $\omega_{4}=1656 \mathrm{~cm}^{-1}$ in the $\mathrm{PhS}-\mathrm{Ag}_{6}$ complex. 


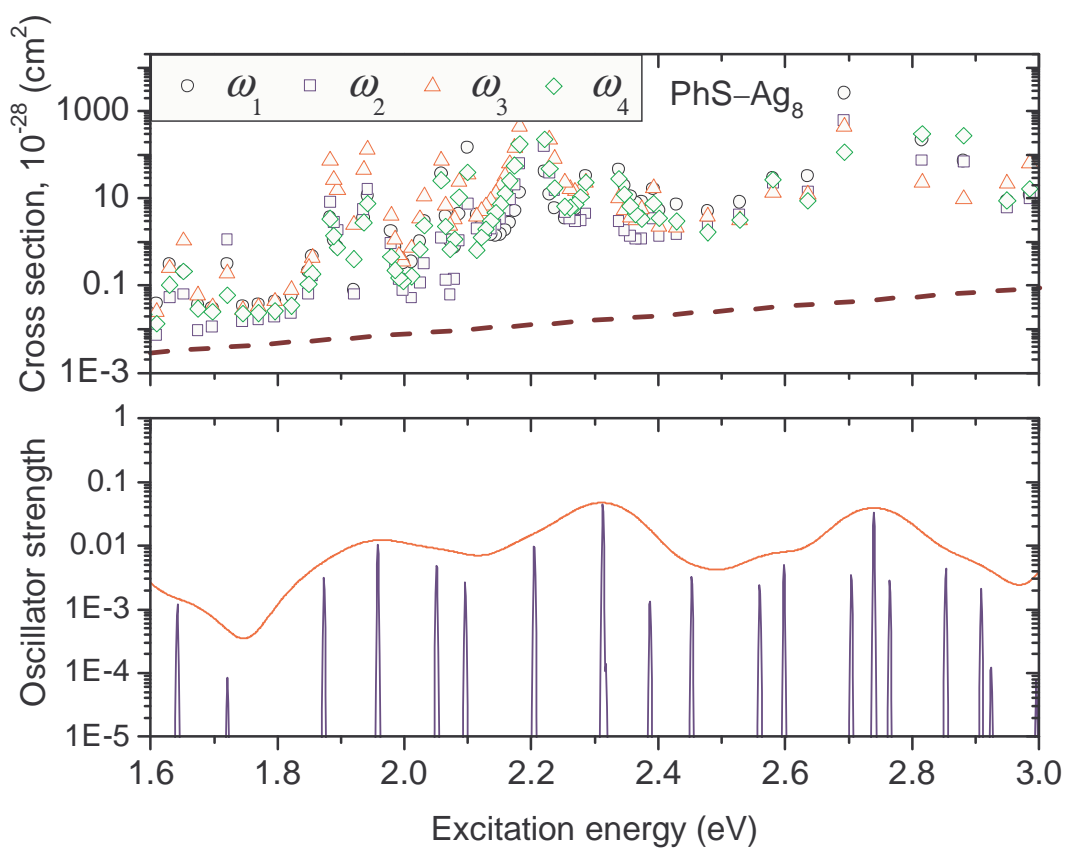

FIG. 13: Raman excitation profile for the vibrational modes $\omega_{1}=1019 \mathrm{~cm}^{-1}, \omega_{2}=1059 \mathrm{~cm}^{-1}, \omega_{3}=1136 \mathrm{~cm}^{-1}$, and $\omega_{4}=1656 \mathrm{~cm}^{-1}$ in the $\mathrm{PhS}-\mathrm{Ag}_{8}$ complex. 


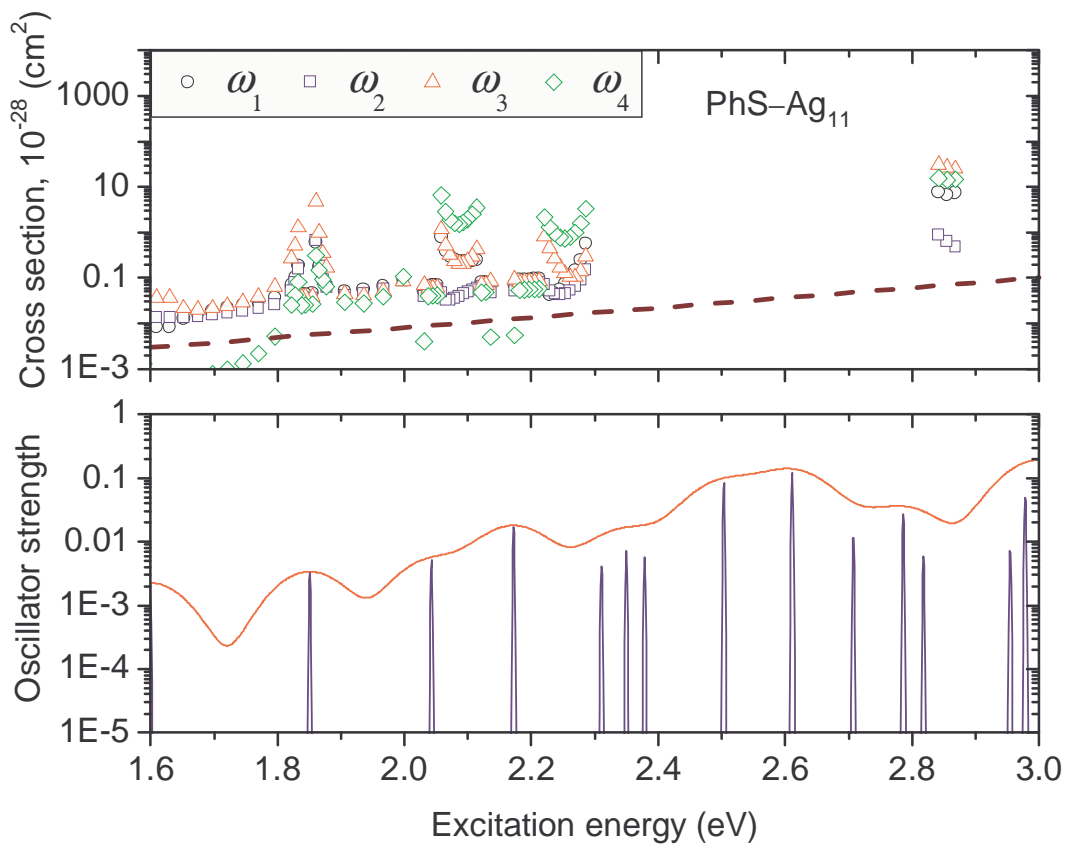

FIG. 14: Raman excitation profile for the vibrational modes $\omega_{1}=1019 \mathrm{~cm}^{-1}, \omega_{2}=1059 \mathrm{~cm}^{-1}, \omega_{3}=1136 \mathrm{~cm}^{-1}$, and $\omega_{4}=1656 \mathrm{~cm}^{-1}$ in the $\mathrm{PhS}-\mathrm{Ag}_{11}$ complex. 